Portland State University

PDXScholar

Winter 3-7-2016

\title{
The Impact of Daily 5 and CAFE Literacy Framework on Reading Comprehension in Struggling Fourth Grade Readers: A Case Study
}

Sandra Lee Duty

Portland State University

Follow this and additional works at: https://pdxscholar.library.pdx.edu/open_access_etds

Part of the Curriculum and Instruction Commons, and the Educational Leadership Commons Let us know how access to this document benefits you.

\section{Recommended Citation}

Duty, Sandra Lee, "The Impact of Daily 5 and CAFE Literacy Framework on Reading Comprehension in Struggling Fourth Grade Readers: A Case Study" (2016). Dissertations and Theses. Paper 2710.

https://doi.org/10.15760/etd.2706

This Dissertation is brought to you for free and open access. It has been accepted for inclusion in Dissertations and Theses by an authorized administrator of PDXScholar. Please contact us if we can make this document more accessible: pdxscholar@pdx.edu. 
The Impact of Daily 5 and CAFÉ Literacy Framework on Reading Comprehension in Struggling Fourth Grade Readers: A Case Study

\section{by}

\section{Sandra Lee Duty}

A dissertation submitted in partial fulfillment of the requirements for the degree of

Doctor of Education

in

Educational Leadership: Curriculum and Instruction

Dissertation Committee:

Dannelle D. Stevens, Chair

Joanne Cooper

Sue Lenski

DeLys Ostlund

Portland State University

2016 
C) 2016 Sandra Lee Duty 


\begin{abstract}
For decades, struggling readers have been a central focus of American public schools. In the United States, many students who struggle with reading comprehension are not receiving high-quality instruction that ensures comprehension of text. Elementary teachers are faced with the challenge of how to structure and organize literacy instruction that ensures growth in reading comprehension for struggling students.

The purpose of this case study is to explore the impact of a reading framework on fourth grade struggling students' reading comprehension, attitudes and engagement. This case study looks specifically at the impact of the Daily 5 and CAFÉ literacy framework that seems to respond to the needs of struggling students and includes Oregon state standards in literacy.
\end{abstract}

The fundamental research questions that guided this study are: (a) How do struggling students perceive their experience in Daily 5 and CAFÉ reading framework, (b) How do struggling students respond to the comprehension strategies taught in the Daily 5 and CAFÉ reading framework, (c) What are struggling students' attitudes toward reading, and (d) What kind of growth in reading comprehension did the struggling students have over one year? This case study used a constructivist and transactional theoretical lens.

Data collected include: interviews, surveys, questionnaires, Draw-a-Reader, journals, and achievement tests. The main finding indicates that fourth grade struggling students made progress in reading comprehension when they engaged in Daily 5 and 
CAFÉ framework. In addition, findings indicate that their progress was facilitated by certain conditions: (a) letting students choose their reading and writing materials, (b) helping student select explicit reading goals, (c) setting up a positive and supportive classroom environment, and (d) offering opportunities for students to collaborate with each other while reading.

The results of this study suggest that the Daily 5 and CAFÉ combined literacy framework benefits struggling readers by producing positive results in reading comprehension as well as contributing to better student attitudes and increased student engagement. With the ever-increasing importance placed on United States National Common Core Standards and Smarter Balanced Assessments as well as the need to address the reading challenges for struggling readers, the Daily 5 and CAFÉ combined literacy framework offers hope for students and teachers alike. 


\section{Dedication}

This work is dedicated to students in my fourth grade classroom who struggle with reading comprehension. May I observe, listen, teach, and help all students become active, engaged, and successful readers. 


\section{Acknowledgements}

Foremost I would like to express my gratitude to Dr. Dannelle Stevens, the chairperson of my committee, for being a consistent role model and advocate, ever patient and encouraging. I was honored to be guided through the process by a researcher and writer of such high caliber.

I also profoundly thank my committee members: Dr. Joanne Cooper, Dr. Susan

Lenski, and Dr. DeLys Ostlund. Such a varied and rich insight was a true gift through this process. Specifically, I am grateful for Dr. Joanne Cooper's optimism and support, along with her expertise in qualitative research. I also appreciate Dr. Susan Lenski's literacy expertise, willingness to guide me with her knowledge in literacy theory and methodology. Finally I appreciate Dr. DeLys Ostlund for her interest in this work and guidance. It has been an honor to work with you.

I am grateful to my colleagues Elizabeth DuBois, Susan Duncan, Patrizia Mastine, Michelle Aldama, and Neera Malhorta for checking in with me, our writing class with Dr. Cooper, and sharing laughter and frustration. This is a collaborative process after all.

Finally, David Gutzalenko, for your support from home, zest for new ideas, and love of learning. This was indeed your sacrifice too. 
Table of Contents

Page

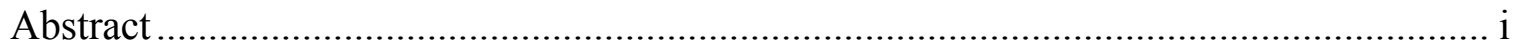

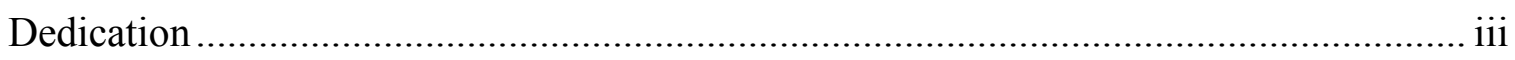

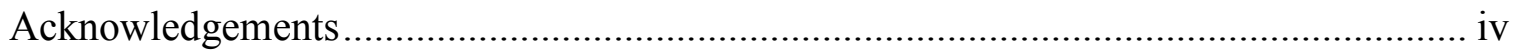

List of Tables .................................................................................................... vii

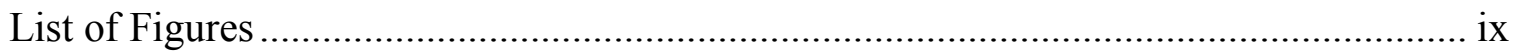

Chapter

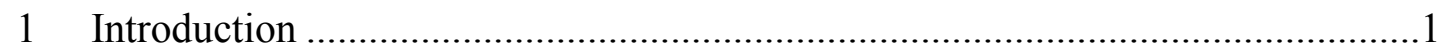

Problem Statement ........................................................................

Background of the Problem ..............................................................5

Statement of the Research Focus .......................................................11

Significance of the Research........................................................20

Presentation of Methods and Research Questions .................................22

Definitions of Key Concepts.........................................................23

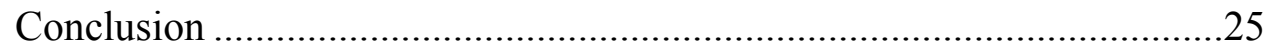

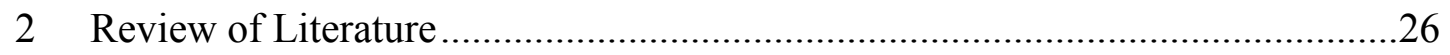

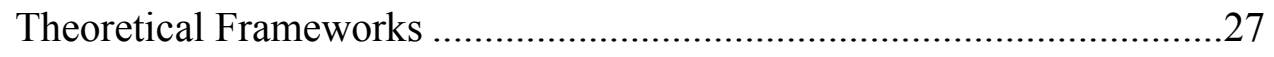

Review of the Theories of the Teacher's Role in Reading

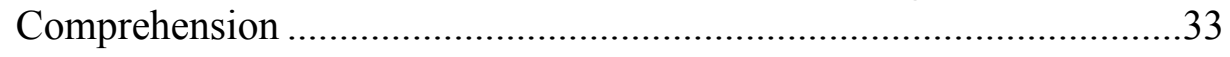

Review of Research on the Daily 5 and CAFÉ Reading Framework........39

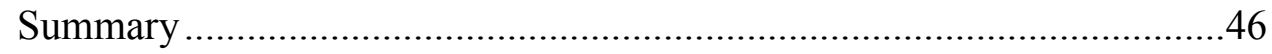




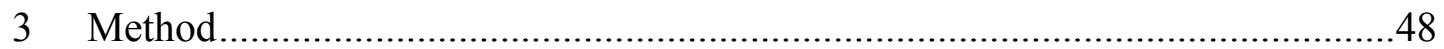

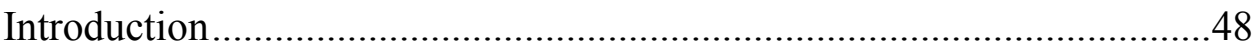

Research Questions and Method-Type: Case Study Approach ..................48

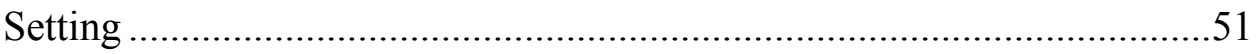

Participants: Selection...........................................................................52

Participants: Sampling ………………………………….....................56

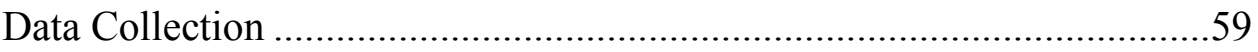

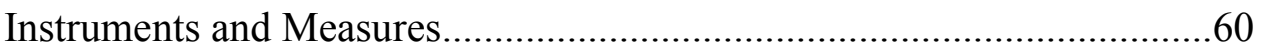

Role of the Researcher …….................................................................62

Data Collection and Analysis.................................................................62

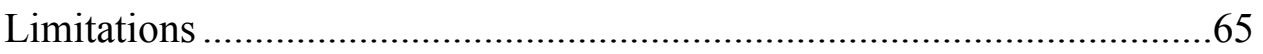

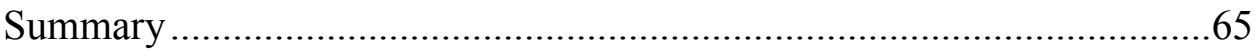

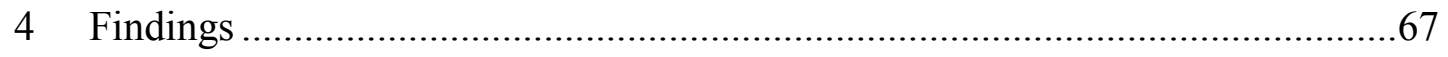

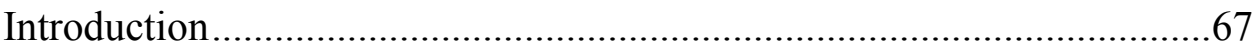

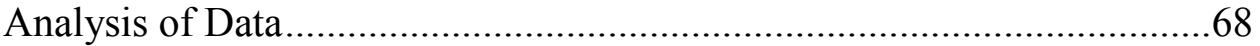

Presentation of Results-Interpretations of Findings ...................................70

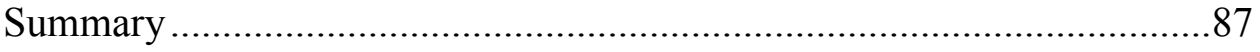

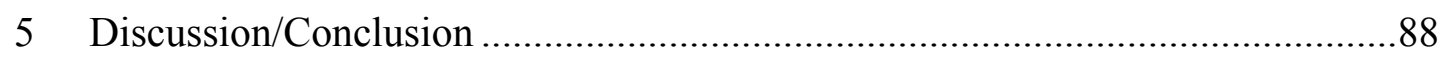

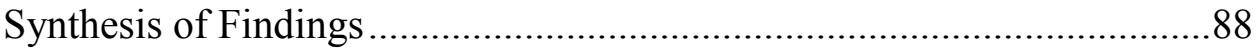

Implications for Classroom Practice .........................................................96

Recommendations for Future Research .................................................98

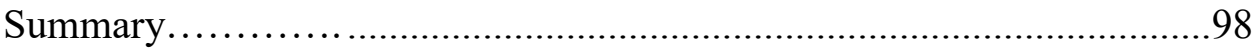




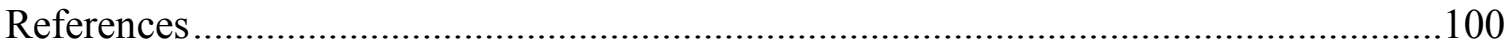

Appendices

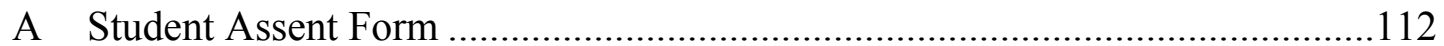

B Consent Form for Parents and Guardians .................................................114

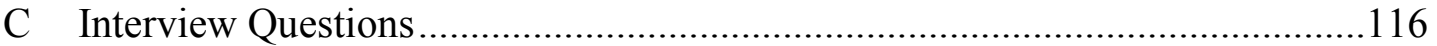

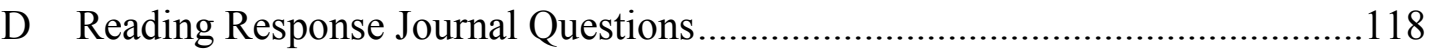

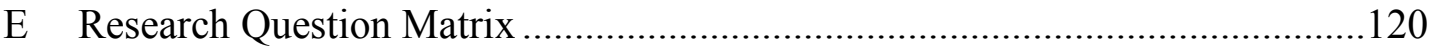

F Student Draw-a-Reader Illustration............................................................ 122 
List of Tables

Table $\quad$ Page

1 Question \#1-Journal Response for CAFÉ Strategies, Reading, and

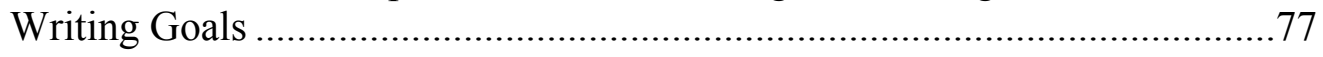

2 Question \#4-Reading Achievement Test Scores .........................................86 


\section{List of Figures}

Figure

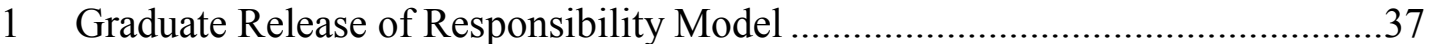

2 Question \#2-Interviews for Goal Setting, Writing Workshop...........................79

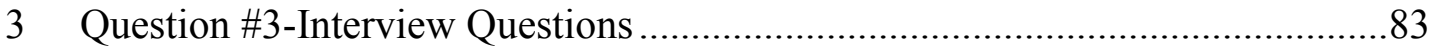




\section{CHAPTER 1 \\ INTRODUCTION \\ Problem Statement}

Reading comprehension is a key factor in academic success, and fourth grade is the year when students begin to concentrate on comprehension rather than just decoding words (Chall, 1983). In the United States, studies have indicated that many students who struggle with reading comprehension are not receiving high-quality instruction that ensures comprehension of text (Allington, 2012). Teachers of different experience levels deliver reading comprehension instruction in a variety of ways. As a result, elementary teachers are faced with the challenge of how to structure and organize literacy instruction that ensures student improvement in reading comprehension. Yet, there are many ways to engage students in literacy learning that will increase comprehension (Boushey \& Moser, 2014). Because reading comprehension is crucial for all students and because I teach fourth grade when the focus becomes comprehension, I am determined to find ways to help my students, especially my struggling students, comprehend and become more engaged in reading.

The purpose of this case study is to explore the impact of a reading framework on fourth grade struggling students' reading comprehension, attitudes and engagement. This qualitative case study defines, describes, and analyzes in what ways the Daily 5 and CAFÉ (an acronym for comprehension, accuracy, fluency, and expand vocabulary) literacy framework (Boushey \& Moser, 2014) impacts fourth grade students who struggle 
with reading comprehension. A literacy framework includes a system of daily literacy instruction and a program where students independently and collaboratively practice a set of comprehension strategies. The study was guided by the following research questions:

1. How do struggling students perceive their experience in Daily 5 and CAFÉ reading framework?

2. How do struggling students respond to the comprehension strategies taught in the Daily 5 and CAFÉ reading framework?

3. What are struggling students' attitudes toward reading?

4. What kind of growth in reading comprehension did the struggling students have over one year?

When my teaching career began more than 30 years ago, I was particularly aware of the challenges and enjoyment in teaching students to read and to construct meaning from text. I also know that I work with a wide range of reading abilities from students who arrive in the United States knowing little English, to students who struggle to read words and, finally, to students who read all the books in the classroom. In addition, I need to balance their needs with the expectation that I meet state literacy standards and reading goals in my school district (National Reading Panel, 1999).

If you had visited my classroom during reading instruction in my first years of teaching, you would have seen children at their desks in ability groupings working on worksheets or at literacy centers working on projects. Other students would have been sharpening pencils and talking to students at the centers. During class reading time, I work with six students while others are working at reading centers. Even though I was working with those six students, I was often distracted by the others not in the group who were supposed to be working independently at reading centers. My attention was divided 
between trying to work with the small group while watching the centers, monitoring worksheets and approving bathroom breaks. Reading instruction time became more about management and less about learning.

Near the end of the day, I became overwhelmed by the large number of worksheets that needed to be graded and by organizing the reading and worksheet materials for the centers the next day. Additionally, assignments using dioramas, posters, and boxes filled the room. Students created these assignments while I worked with small groups of students. My weekends consisted of preparation for centers, correcting worksheets, and gathering materials for projects. The amount of children's busywork increased each week and I kept hoping to free up my time to work with small groups. When I administered reading assessments, I was disappointed that my students did not always make as much growth as I expected them to make.

My reading goal today is the same as 30 years ago: all students will learn to read and comprehend. The question is about how to manage 35 students during reading instruction while differentiating instruction to improve reading comprehension. Additionally, how do I meet each individual's reading needs during reading instruction (Boushey \& Moser, 2006)?

Many factors contribute to increasing student reading comprehension. Boushey and Moser (2006) emphasized the need to build a reading framework such as Daily 5 that will help students learn to comprehend what they read and develop the daily habits of reading. Allington (2009) supported daily habits of reading stating that students should spend at least 90 minutes per day in high-success reading. Boushey and Moser reaffirmed 
that reading for extended periods of time, reading discussion with peers, and student reading choice help students increase reading comprehension. Duke and Carlisle (2011) further supported the method of giving students a choice with text volume and range of texts to read independently. Boushey and Moser noted that the search for a better way to help students become better readers has continued for years.

I have joined the search for better reading instruction strategies as well. However, if you enter my classroom today, you will see something quite different from what I describe above. Students are reading books quietly from their book boxes. Students take turns reading to each other from a Time for Kids magazine. Students are at a writing table editing each other's work. Students sit in a beanbag chair with a headphone using an iPad to read a poem. These activities are part of the Daily 5 and the CAFÉ literacy framework. As students are immersed in this literacy framework, I work with a small group of students sitting on the floor. The remaining students are working by themselves independently in the activities described above.

Boushey and Moser (2006) emphasized that comprehension is a complex process for students as well as a challenge for elementary school teachers. Since comprehension is a concern in elementary schools, Kucer (2001) asserted that comprehension instruction in the elementary classroom requires specific training. Duke and Carlisle (2011) believe that many factors lead to an increase in student reading comprehension. Some of the factors are the integration of reading and writing activities, implementation of differentiated instruction, attention to vocabulary and language knowledge, instruction in reading comprehension strategies, and student engagement during reading discussions. 
While educators for many years have agreed that reading comprehension is important (Durkin, 1978), there is little agreement about which of the many complex factors that contribute to comprehension work best, such as, how to manage the classroom for effective reading instruction, how to meet the individual needs of all students to ensure reading comprehension and what reading framework would meet these needs. For certain students, often called struggling students, the lack of comprehension is especially important since their lack of progress snowballs over time (Snow, Burns, \& Griffin, 1998). The less they read; the less they learn in every subject. One problem in practice is while a number of students struggle to comprehend text, that there is little agreement about which methods would work best, especially for struggling students. It is, therefore, important to examine different reading frameworks to see what impact they have on reading comprehension, attitudes and engagement, especially for our struggling readers. The purpose of this case study is to explore the impact of a reading framework on fourth grade struggling students' reading comprehension, attitudes and engagement.

\section{Background of the Problem}

\section{Definition and Description of Reading Comprehension}

Reading is the foundation for lifelong learning. One must be able to master the skill of reading comprehension in order to excel at other parts of the learning process. In today's world, employment, academic success, and personal accomplishment depend on reading proficiency. Reading is not just words on a page; reading is connected to previous knowledge (Luke \& Freebody, 1999). Teaching students to read and comprehend is one of the fundamental responsibilities of schooling, and literacy is an 
essential right of every student as well as the basis for lifelong learning (Armbruster, Lehr, \& Osborn, 2001).

The definition of reading comprehension is not simple. Reading comprehension is a complex, cognitive process that is constructed through collaboration with the reader and text (Durkin, 1978). Reading is also an active, integrated process of problem solving through which readers make sense of texts (Luke \& Freebody, 1999). Luke and Freebody (1999) suggested that readers draw on a menu of practices when they read. Readers participate in an active process to understand text, use strategies to understand what they read, critically analyze texts, and use texts purposely.

When reading, decoding the symbols into words, that is, just saying the words, is not enough. One must be able to understand what one has read and be able to apply the newly acquired knowledge for the benefits of reading to be fully realized (Hoyt, 2009). Reading comprehension is the capacity to understand the meanings communicated by texts. The primary goal of reading is not just decoding but comprehension. Hoyt (2009) stated that when constructing sensory images in our mind, determining importance, or making an inference, we boost ourselves beyond rote level "decoding" and enter a place where reading is purposeful, thought provoking, and often entertaining. Good readers are purposeful, active, and use strategies to construct meaning before, during, and after reading (Armbruster et al., 2001; Johns \& Lenski, 2005). Duke and Pearson (2002) suggested using comprehension strategies such as questioning, inferring, determining importance, visualizing, and synthesizing to improve reading comprehension. Students in elementary school may learn reading comprehension strategies through teacher direct 
instruction and models that shift student learning gradually from teacher to student (Pearson \& Gallagher, 1983).

In a study about reading comprehension Tivnan and Hemphill (2005) observed students from 16 elementary schools from high-poverty neighborhoods. Teachers in one school by the end of the year had $80 \%$ of their students at grade level in reading comprehension while in another school in the same school district, only $20 \%$ of their students were at grade level at the end of the year. Yet, the researchers found that there was not one literacy model clearly associated with higher comprehension scores. There seem to be many factors that may foster student comprehension such as instruction linked to student needs and interests.

There are many other factors that affect comprehension. Brain biology is one of them. Developments in neuroscience and technology are able to identify areas and neural pathways the brain uses for reading (Snow et al., 1998). Reading instruction benefits from brain science by indicating that brain-based instructional practices and policies seem to lead to increased comprehension (Snow et al., 1998). Memory and attention, sentence structure in a given work, and a person's vocabulary-all impact reading comprehension (Van den Broek \& Kremer, 2000). Reading comprehension is an ambitious task that involves a process of constructing meaning in which working memory's exclusive tasks play an important role (Ericsson, 2003). Working memory is a biological function in which the memory holds multiple ideas or bits of information that can be manipulated (Ericsson, 2003). 
Ericsson (2003) noted that researchers from Northwestern University have discovered brain activity supporting the process of higher-level comprehension. Ericsson also found that, if there is poor reading comprehension, brain activity remains the same as if the person were not reading. There is no surge in brain activity. In comparison, students with high comprehension show a surge in brain activity during reading. As we learn more about brain research and reading comprehension, we may be able to use brain-based assessments to investigate whether reading programs and instructional methods are effective at improving reading comprehension (Ericsson, 2003).

Culture, school, and home affect reading comprehension as well. Interactions between reader, text, and motivation to read interact with a person's cultural background in a sociocultural context and influence reading comprehension (S. D. Miller \& Faircloth, 2009; Moje et al., 2004). The sociocultural context includes communities in the school setting, peer groups, home life, and school relationships (S. D. Miller \& Faircloth, 2009; Moje et al., 2004). Lonigan (2003) reported that low-income children engage in fewer language and literacy experiences during preschool years. Hart and Risley (2003) emphasized that children on welfare experience less listening and speaking with parents than the average working-class child. In addition, children from working-class families experience less than one third of the average vocabulary at home as the child in a professional family. Because language and early reading skills are important to teach in elementary grades, teachers need to have instructional strategies to teach meet the needs of all students whatever their background (Moats, 1995). Readers with poorly developed vocabulary and decoding skills may not have the tools to comprehend text. Instruction 
and classroom reading community become necessities for student reading development and learning processes. Therefore, classroom environment and instruction are important to strengthen the social context of student learning to read (J. S. Brown, Collins \& Duguid, 1989).

Other factors affecting reading comprehension are lack of background knowledge and vocabulary for readers to comprehend texts (Pardo, 2004). Fisher and Frey (2009) suggested that, when students lack the background knowledge, students may not understand keywords or how sentences relate to each other and therefore may not be able to comprehend text. Pardo (2004) asserted that if students know about background knowledge in a subject, they understand the subject as they read. Struggling readers often come from literacy environments where there is limited prior knowledge, less oral language development, and lower emergent literacy skills (Brooks, Hamann, \& Vetter, 1997; Brownell, 2000). Qian (2002) asserted that there is a strong correlation between background and vocabulary knowledge in successful reading comprehension.

Motivation is another important factor in student comprehension. Vygotsky (1962/1986) reminded us that the social aspect of learning is unlimited, especially as students work in small groups that are engaged in meaningful reading. Guthrie and Wigfield (2000) agreed that when interesting texts have real-world application, reading motivation increases. Thus, they recommend that students receive a range of choices in what they can select to read. There is strong evidence that student choice of reading texts contributes to motivation (Jimenez \& Duke, 2011). A study by Jimenez and Duke (2011) on student text choice in fourth grade students used surveys about expository texts they 
liked to read. The results of student surveys showed a greater number and range of comprehension processes in students who were given choice of which text to read (Jimenez \& Duke, 2011).

Difficulty in reading fluency may contribute to problems in reading comprehension as well (Parker, Hasbrouck, \& Denton, 2002). Reading fluency is defined as the ability to read with speed, accuracy, and proper expression (Rasinski, 2006). When students spend large amounts of time trying to decode words, fluency declines, short-term memory loss occurs and memory is not available for comprehension (Brownell, 2000). Pardo (2004) supported regular, independent reading time to increase reading fluency to increase comprehension. When a student is a fluent reader, the student decodes words easily and more of the reading process may be devoted to comprehension (LaBerge \& Samuels, 1974; Perfetti, 1985). Catts, Hogan, and Adolf (2005) suggested that fluency is important; yet, speed is not the only indicator of comprehension problems. When readers are able to recognize words quickly, their remaining cognitive resources are available to comprehend meaning (Logan, 1997).

Finally, there is evidence that the "strength" of the teacher and the choice of teaching strategies have a strong impact on reading comprehension. The strength of teacher involves the pedagogy she chooses and skill in delivering reading instruction. In one reading comprehension study it was established that second through fifth graders made significant gains in reading comprehension over the course of a school year not only specific teaching practices but also because of teacher strength (Taylor, Pearson, Peterson, \& Rodriguez, 2003). 
To summarize, reading is the foundation for lifelong learning. In order to build this foundation, understanding what one reads is important. Comprehension is attained through successful interaction between reader and text. The issues in reading comprehension are many, especially with struggling readers. Many factors affect the comprehension process, including a student's sociocultural environment, background knowledge about the subject matter, motivation, reading fluency, and teacher "strength" or effectiveness. In particular, how to increase reading comprehension for struggling readers continues. My question is about the impact of a specific literacy framework and its effect on the reading comprehension of struggling readers.

\section{Statement of the Research Focus}

My research focus is to explore the impact of two reading comprehension strategies embedded in one reading framework in my fourth grade classroom. The components in this framework are the Daily 5 and the CAFÉ system (Boushey \& Moser, 2006). In particular, I will use this framework to focus on students who struggle with reading comprehension. Both of these strategies focus on "the gradual release of responsibility" for reading that is furthered by teacher modeling, guided practice, student practice, and student independence (McLaughlin \& Allen, 2009).

\section{The Daily 5: First Component in the Reading Framework}

Daily 5 method is embedded in a pedagogy that Boushey and Moser (2006) designed to help students develop daily habits of reading, writing, building vocabulary and working independently. Daily 5 offers teachers a pedagogy to use when instructing students in the five reading- and writing-related tasks. The Daily 5 in literacy framework 
is simple and flexible. Within the Daily 5, student independence is encouraged. Teachers are free to use the framework in a way that best fits the needs of their students (Boushey \& Moser, 2012). Students may participate in reading and writing for long or short periods of time, acquire instruction on becoming independent, and have individual instruction tailored to meet their needs (Boushey \& Moser, 2006). After students practice and learn the habits, the Daily 5 is student-driven and is intended to engage students in all aspects of reading and writing (Boushey \& Moser, 2006).

Daily 5 consists of five literacy activities that begin with a 15-minute whole group mini-lesson followed by a 60 -minute independent work time. During the work time, students are able to make a choice to engage in one of the five activities (read to self, read to someone, work on writing, listen to reading, vocabulary work) while the teacher meets with individual students in conferences or gives instruction using guided reading groups. According to Boushey and Moser (2006), the traditional literacy instruction may consist of a teacher-driven model that relies on worksheets as well as reading and writing activities that do not integrate with other academic subjects. Daily 5 integrates with other subjects such as science, social studies, and health. The integration occurs as students read and write using reading materials from other academic subjects. An example would be the use of magazines, newspapers, and technology. The Daily 5 approach encourages student literacy learning by using whole group and small group instruction rather than whole group instruction exclusively. Students participate in purposeful practice and apply literacy skills. 
Along with the Daily 5, CAFÉ (Boushey \& Moser, 2006) is the second element in the reading framework I will use in this study. As students work in small groups of four to six during Daily 5 center rotations, the teacher offers mini-lessons using the CAFÉ system (comprehension, accuracy, fluency and expand vocabulary) to small groups of students. Each Daily 5 center rotation lasts 10 minutes. While I use the CAFÉ system, the other students practice the lessons in individual reading and writing tasks such as reading to self, reading to another student, listening to reading, working on writing, and word work. For example, during the read-to-self part of CAFÉ, the student selects a book from the classroom library and chooses where to read in the classroom-at her desk, the beanbag or on a sofa. At the same time two other students select books and read together in a different classroom space. Meanwhile, even others use iPads and laptops during "listen to reading." Throughout Daily 5, students may choose writing workshop or vocabulary activities at a center. Within writing workshop, students use journals and specific writing strategies to complete their work at a table. Vocabulary activities include student use of whiteboards, markers, technology, dictionaries, and vocabulary books. Students in Daily 5 rotations are located in various places throughout the room: some are reading alone and others are reading in pairs. The remainder of students met with me in a small group.

The practice of grouping students by reading abilities and different skill levels in order to promote reading comprehension started in the 1950s (Barr \& Dreeben, 1991). In contrast, Daily 5 does not group students by reading level. Allington (1983) described a differentiated system of teaching reading comprehension that occurs among groups of 
students which meets the needs of all students but, does not group students by reading level. Daily 5 allows teacher time with individual student conferencing while other students are working in the reading framework; thus, meeting individual student needs.

The Daily 5 core elements are designed to promote meeting the individual needs of all students (Boushey \& Moser, 2014). In fact, Boushey and Moser (2014) argue that the Daily 5 promotes a differentiated system of teaching reading comprehension. The core elements of Daily 5 include creating trust and respect, focusing on community, giving opportunity to choose books to read, requiring students to be accountable for work done, and leading students in transitions from one reading task to another for brain and body breaks. I will now discuss each of the core elements of the Daily 5 program.

Trust and respect are the first set of elements in the foundation of the Daily 5 framework (Boushey \& Moser, 2014). Roehler and Cantlon (1997) claimed that explicit modeling in which the teacher demonstrates how to learn a specific reading routine encourages trust between the student and teacher. Through the 10 steps of independence in which students learn routines day after day, students begin to experience trust in their ability to choose what is best for them to read. I demonstrate and students practice the 10 steps of independence during which students acquire skills to become independent learners, and trust builds between student and teacher (Boushey \& Moser, 2014).

Another foundational element is learning in a community. Cazden, John, and Hymes (1972) acknowledged that learning in a community is a social activity that leads to higher reading achievement. Vygotsky's (1930/1978) constructivist theory views learning as social activity when a teacher and students engage in conversation. Many 
opportunities are provided for oral language to occur during Daily 5 instruction. Madden (1988) claimed that poor readers make improvement during reading in a community setting where all readers work together. Almasi and Gambrell (1994) emphasized social interaction in the community of elementary school classrooms as students interact during literature discussions. In the Daily 5 reading framework, students read with a partner in the comfort of a community that honors each student and fosters learning as a social activity (Boushey \& Moser, 2014).

The third foundational element in the Daily 5 is student opportunity to make choices in reading over what they learn, and how they learn it. Boushey and Moser (2014) said choice allows students to take ownership of their own learning. In the Daily 5 framework, students are able to make choices what they read, where they sit, and which activity they participate in. During the Daily 5 literacy framework, students move from teacher modeling reading behaviors to student practice individual or in small groups. Once trust is established between teacher and student, students work in a community where students have conversations about reading. The conversations may contribute to the research question about student perspectives of Daily 5. Trust and community in the social activity of reading builds choice for students (Boushey \& Moser, 2014). Choice becomes part of the success of Daily 5. The research question about student choice and how does student choice motivate struggling readers to participate in Daily 5 is related.

Accountability is the fourth element in the foundation upon which the Daily 5 is built. Through the process of modeling reading behavior in the steps to independence, students no longer need management from the teacher such as worksheets and projects. 
The accountability is in the student ability to self-select books that results in engagement and achievement in reading (Gambrell, 2011).

Boushey and Moser (2014) suggested that the combination of using brain research with brain-compatible learning is the fifth core element in implementation of Daily 5. Boushey and Moser (2006) argued that students who are able to sit for 10 minutes of instruction need to make a slight shift to refocus after 10 minutes. In earlier research on accountability Anderson, Wilson, and Fielding (1988) studied a group of fifth graders and the amount of time engaged in reading each day. The lowest performing students read the least amount each day and read very few vocabulary words. In this research, the effects of increased amounts of reading time affected reading achievement. Routman (2003) suggests that focus lessons should be $20 \%$ of the time while $80 \%$ of the time should be spent on practice of the concept when students are engaged in reading. Routman (2003) found that the students who scored in the highest percentile read the most each day. The lowest performing students read the least amount each day. In this research, the effects of increased amounts of reading time affected reading achievement. The argument about increased amount of reading time devoted to reading continues to support Daily 5 as brain research says increased amount of reading affects students' achievement in word exposure.

Brain research indicates that students perform well if they are engaged in instruction for about 10 minutes and practice for the remainder of the time (Grinder, 1995). In the Daily 5 and CAFÉ transitions take place between the workshop structure of read to self, read to others, listen to reading, vocabulary work, and work on writing. 
Students have opportunities to take a short break (5 minutes) and refocus. During the short break, students are able to move to another location, choose a different book, or engage in physical movement (Boushey \& Moser, 2014).

Undergirding the above core elements of the Daily 5 are the ten steps to teaching and learning independence. Boushey and Moser (2014) argued that the ten steps set the Daily 5 apart from other workshop and management systems and lead to a reader's growth in literacy. Grinder's (1995) asserted that the brain receives input from visual, auditory, and kinesthetic memory systems. The kinesthetic system supports the longest lasting memory. The ten steps to teaching and learning independence attend to the visual, auditory and kinesthetic systems by including:

- students verbally setting a purpose (auditory),

- students demonstrating desirable behaviors (kinesthetic),

- students practicing and building reading stamina (kinesthetic),

- students reflecting on their reading alone and with others (auditory),

- students choosing where to read around the classroom (visual, kinesthetic). These steps echo Palincsar and Brown's (1984) earlier research on supportive scaffolds for reading comprehension. This ten-step approach is learner-centered and provides opportunities for feedback. Learning occurs in the community of learners.

The difference between Daily 5 pedagogy and other methods of teaching reading and writing is in the progression of student dependence to independence during the Daily 5. In Daily 5, reading is taught, modeled, and practiced. Teachers set goals and objectives, and then set the purpose. Next, desired behavior during independent reading is 
modeled by students with teacher guidance and is posted on a chart in the classroom. Students are able to make choices about where they are placed around the room. Students select a variety of seating arrangements in order to engage in reading and writing. Students practice reading and build stamina. At the end of the lesson, students gather back together, conduct a group check-in and use self-evaluation (Boushey \& Moser, 2006).

\section{CAFÉ: The Second Component in the Reading Framework}

The acronym CAFÉ stands for comprehension, accuracy, fluency, and expanding vocabulary. Once the Daily 5 framework is taught and implemented in the classroom, CAFÉ concepts are taught in mini-lessons. Students are able to practice the lessons from CAFÉ during Daily 5 rotations where students read to self, read to others, listen to reading, work on writing, and improve vocabulary. These concepts are critical to reading and reading instruction (Boushey \& Moser, 2006).

CAFÉ is a visual aid of skills and strategies under the four concepts of comprehension, accuracy, fluency, and expanding vocabulary. The categories of CAFÉ are based on reading instruction: comprehension, phonics and phonemic awareness, fluency and vocabulary. The categories of CAFÉ are a reminder for students who may need help with reading strategies during their reading experience (Boushey \& Moser, 2012). Boushey and Moser (2006) maintained that, once reading assessments are completed to determine reading fluency, accuracy, and comprehension, CAFÉ is a pedagogy that focuses instruction and guidance before and during reading, 
The CAFÉ pedagogy or system helps students set reading and behavior goals, with their teacher monitoring their progress in reading. Teachers use this system to focus on student needs and goals and to keep records in this age of educational accountability. Once the reading assessment is complete, the CAFÉ system also allows teachers to schedule individual conferences and implement literacy instruction using small-group and one-on-one conferences. Once the teacher has taught a mini-lesson lasting no more than 10 minutes, the students work in the Daily 5 reading rotations to practice reading strategies taught during the mini-lesson. When the reading comprehension goals are identified, students receive differentiated instruction based on their needs. CAFÉ pedagogy focus is on reading strategies, student reading goals, writing goals, and vocabulary instruction. In contrast, other reading programs do not provide time each day to meet with six individual students to discuss reading strategies and writing goals. The assessment is the first step in identifying student reading achievement to implement reading instruction about best practices in reading comprehension (Boushey \& Moser, 2006).

The CAFÉ framework, unlike a program where each component is dictated by the reading adoption, uses assessment and manages reading instruction to coach and support students (Boushey \& Moser, 2009). Teachers are able to implement the differentiated instruction necessary for each student (Boushey \& Moser, 2009). Differentiated instruction for all readers and strategic support may ensure greater independence and selfreflection in each student. As each reading strategy and skill is taught in mini-lessons, teachers keep records of documentation on each individual student with the skills and 
instruction each student needs. The strategies are posted on the CAFÉ visual aid so students are able to access the strategy information. The visual aid is posted in the classroom so students understand the acronym.

The reading focus for this study is then on the impact of two research-based activities (Daily 5 and CAFÉ) on the reading comprehension of fourth grade students who struggle to comprehend what they read.

\section{Significance of the Research}

The goal of making "every child a reader" depends on effective reading instruction (Allington, 2012). Allington (2012) argued that, when reading instruction is effective, the instruction does not always have to use significant amounts of neither time nor money. Yet, many students do not receive the most effective instruction because educators make decisions that do not lead students to become successful readers.

There is a lot of research on reading comprehension but not always on what teachers should do to implement the research-based strategies. Onofrey and Theurer (2007) and Liang and Dole (2006) contend that in many studies of research on reading comprehension, teachers are still puzzled about how to implement instruction. Many teachers use manuals and textbooks that use assessments and give curriculum directions. However, these do not include how to design lessons that help students comprehend from different texts.

Research on the impact of the Daily 5 pedagogy and CAFÉ framework of reading comprehension strategies can help teachers make informed decisions about which pedagogies to adopt to address the needs of all learners, especially struggling students 
(Boushey \& Moser, 2012). When teachers understand how a reading framework might impact reading instruction, especially for struggling students, more students may be able to make progress in literacy.

In the Daily 5 pedagogy, there are instructional books that compare the Daily 5 and CAFÉ framework to many components of a prescriptive reading curriculum. Once teachers are able to implement and use comprehension strategies from the CAFÉ framework, they may be able to teach students, especially struggling students, how to be effective at comprehending nonfiction and fiction texts (Boushey \& Moser, 2009).

The topic of my research is about testing the efficacy of Daily 5 and CAFÉ, especially for struggling readers. Boushey and Moser (2006) argue that when designing effective comprehension instruction, teachers need to understand how each individual student comprehends by using information grounded in theory and research.

Reading is a foundational skill in life. The ability to read opens doors in life and fosters opportunities for engagement in the workforce and participation in the community as a citizen. To address the problem of lack of reading comprehension, early interventions, individualized literacy tutoring, and trained reading teachers are necessary to help comprehension problems (Snow, Barnes, Chandler, Hemphill, \& Goodman, 1991). Best practices in literacy instruction may include monitoring individual student progress and implementing differentiated instruction based on literacy research for individual students (Duke, Bennett-Armistead, \& Roberts, 2003). All of the activities in the Daily 5 and CAFÉ seem to be the foundation for improved reading comprehension and engagement. 
Reading effectiveness is a goal for both literacy researchers and literacy educators. The significance of this study is that the model has the potential to improve literacy teaching and learning that, can help address societal problems in schools, communities, and states. Daily 5 and CAFÉ provide a framework and a system that aim to improve comprehension in the classroom especially with struggling readers.

\section{Presentation of Methods and Research Questions}

The purpose of this case study is to assess the impact of a reading framework on fourth grade struggling students' reading comprehension, attitudes and engagement. The problem is that students with low comprehension are not making progress in reading comprehension. Therefore, this qualitative case study defines, describes, and analyzes how a reading framework that includes the Daily 5 and CAFÉ literacy structures (Boushey \& Moser, 2006, 2009, 2014) impact students in a fourth grade class who struggle with reading comprehension.

Case study research looks at classroom phenomenon and examines the practice in depth (Hatch, 1978). This research provided the opportunity for me to reflect on my teaching practices and become a "field worker," like an ethnographer (Zeichner, 1981). The case study is detailed and gives in-depth descriptions of everyday life and practice; thus, a variety of methods were employed to capture their experiences.

My research case study is a qualitative approach to examine reading comprehension in a fourth grade class with a focus on six struggling readers. The qualitative methods used were: interviews, surveys, student response journals, Draw-aReader, questionnaires and achievement tests (Merriam, 2009). By using a variety of data 
collection strategies I was able to provide a rich description of student experiences as they worked on reading comprehension. The case study began in April 2015 and finished at the middle of June 2015.

Once the data from the transcripts, field notes, tests and documents were gathered, they were organized chronologically according to when they were collected. Yin (2004) stated that analysis occurs once the data is collected. Yin described a two-step method for analysis consisting of pattern matching and models that show logic in the case study. The data were analyzed according to patterns that emerge.

\section{Definition of Key Concepts}

Comprehension-Comprehension is a process where readers make meaning by interacting with words. Smith (1975) defined comprehension as "relating new experience to the already known. Anything readers cannot relate to what they know already will not make sense; students look up words or read words in context to understand the meaning" (p. 211). In a text it also refers to the viewpoint the reader takes in relationship to the words (Duke, 2003).

Motivation-The literacy definition in terms of school, defined by Brophy (1998) is "the tendency to find academic activities meaningful and worthwhile and to try to get the intended learning benefits from them" (p. 12).

Differentiated instruction-Teachers implementing differentiated instruction are able to teach information and skills multiple times and at varying levels. As a result, learners enter the instructional teaching with different approaches, knowledge, and 
strategies for learning. In differentiated instruction, teachers meet the needs of diverse students (Tomlinson, 2001).

Struggling readers-Students who are struggling readers usually read one or more years below their current grade level but are not identified with a learning disability. They may lack reading skills that other students have and are not able to define vocabulary words or apply comprehension strategies.

Student choice-Students need to be able to make choice in selection of books, places to read in the classroom, and other students to read with. Katz and Chard (1989) argued that when teachers make choices for students such as workbooks, some students will achieve the learning objective, but many will not, since each learns in a slightly different way. Students need a variety of choices in the educational setting.

Daily 5-The Daily 5 is a classroom framework that supports learning. The Daily 5 is a student-driven management framework designed to fully engage students in reading and writing. Students work in one of five elements independently as teachers work with small, guided reading groups and with individual student conferences (Boushey \& Moser, 2006).

CAFÉ-CAFÉ is an acronym for comprehension, accuracy, fluency, and expanding vocabulary. The four components are research-based and critical to reading. CAFÉ is a system to guide and focus instruction. CAFÉ helps students set reading and behavior goals along with monitoring progress (Boushey \& Moser, 2006). 


\section{Conclusion}

Chapter one introduced reading comprehension as a key factor in academic success. The chapter describes the context of the study in a fourth grade U.S. school classroom where students begin to concentrate on comprehension rather than just decoding words (Chall, 1983). The main focus of this chapter is to introduce the problem, define the research questions, provide background information to support the existence of the problem, and describe the focus of the research. The Daily 5 and CAFÉ reading comprehension strategies are combined into a literacy framework that was used in this study to assess struggling fourth grade students' reading comprehension.

The next chapter, chapter two, first presents a theoretical framework for understanding the current research on U.S. elementary school reading comprehension. The constructivist and transactional learning theories are the lens used to explain what happens during reading comprehension. Next, research on reading comprehension pedagogy is examined with a focus on the Daily 5 and CAFÉ framework. 


\section{CHAPTER 2}

\section{REVIEW OF LITERATURE}

In the following chapter, you will find the review of the literature that elaborates on our understanding of the skills and pedagogy undergirding reading comprehension for U.S. elementary school students. The purpose of this case study is to assess the impact of a reading framework on fourth grade struggling students' reading comprehension, attitudes and engagement.

The research problem is that students with low reading comprehension do not make adequate progress in school. In addition, once these struggling students do not learn how to comprehend what they read, their learning of all school subjects suffers. Over time, the effect of lack of reading comprehension snowballs. This case study examines the impact of a literacy framework called Daily 5 (read to self, read to someone, listen to reading, work on writing, and vocabulary work) and CAFÉ (comprehension, accuracy, fluency, and expand vocabulary) on reading comprehension of fourth graders who are struggling with reading. The literature review identifies relevant theoretical, empirical, and practitioner literature in the field of reading comprehension.

The literature review is organized as follows:

1. Discussion of two theoretical frameworks: the transactional theory of reading and writing, and the constructivist theory of learning,

2. Review of the theories of the teachers' role in reading comprehension,

3. Review of research on the Daily 5 and CAFÉ reading framework. 


\section{Theoretical Frameworks}

\section{Transactional Theory-The Reading and Writing Transaction}

One of the theories that guided this research study about how a reading framework impacts struggling readers and improves reading comprehension is transactional theory. Rosenblatt (1978) emphasized that the meaning of any text is not in the work itself, but in the reader's interaction with it, whether it is a novel, fable, or short story. The reader must transact with the text to make meaning. It is when the two transact that meaning occurs. The transactional view indicates that meaning is derived from the context of a given social interaction.

Rosenblatt (1985) claimed that transaction in reading occurs when a particular reader and the arrangement of marks on a page happens at a certain time in a certain context. Therefore, the understanding of the text does not happen ready-made in the text or in the reader, but in the transaction between the reader and the text. We make meaning of a new situation or transaction by reorganizing, revising or extending elements from our personal language. Transactional theory is about who the readers are, what they bring to the text, their expectations of the text, and the choices they make as they read. When it comes to reading comprehension, it is important that a teacher understand the knowledge and experience the student brings to the text in order to make meaning.

According to Rosenblatt (1978), transactional theory takes literacy instruction away from assigned meanings established by teachers, experts, or authors. Transactional theory is not about literacy instruction that uses prescribed methods from teachers or 
experts who assign an experience with literature. Reading transaction is not passive, but active, and the meanings are created when the reader and text come together. Therefore, the text by itself does not contain a single meaning; the text and the reader create meaning and a transaction. The relationship between reader and text is much like the river and its banks, each working its effects on the other. Another example would be student participation in comprehension strategies. Transaction occurs as students model strategies with other students and create new meaning. This transaction occurs during Daily 5 in read to others.

When students respond to the text, reflect on the responses, and analyze them with other students, they are making transactions with other readers as well as the text. The literature classroom environment fosters cooperation and discussion among students. Students are encouraged to engage in book discussions with other students and teachers. The environment is print-rich, active, and integrates technology, art, and projects into comprehensive reading instruction. Lastly, literacy knowledge is expanded in discussion and reflection that may lead to greater knowledge of self, text, and other students.

The writing transaction is much like the reading transaction. Readers approach a text and writers face a blank page to write. Writing is a learning process; a process of discovery. The transaction occurs between the writer and the paper to make meaning of the writing. The writer makes transactions in writing within a personal and social environment. Through the transaction, the writer constructs writing about past experiences and life situations. New meanings emerge out of transaction and experience 
the writer brings to the writing. In a transactional situation of writing, the writer is aware of reading and writing to create meaning.

As students participate in the Daily 5 and CAFÉ framework, students self-select a variety of books to meet their reading needs. Next, teachers demonstrate and model fluent reading and writing so that students learn how to construct meaning from print. The transaction occurs as students choose books, interact with the text, and write for personal and authentic reasons. Since instruction during Daily 5 and CAFÉ goal is transaction with text and constructing meaning, best practices from reading research are substantiated in interactive read-aloud, guided reading, shared writing, independent reading and writing. All of these best practices are part of the Daily 5 and CAFÉ and emphasize reader transaction with text.

\section{Constructivism-Theory of Knowledge}

The second theoretical framework that guided the current study is based on the theory of learning known as constructivism. As an early thinker about learning, Dewey (1933) emphasized the use of real-world application to foster learning, Piaget (1985) claimed that new learning fits the existing knowledge and existing knowledge accommodates new information. Bruner (1986) echoed these earlier ideas and described the process of learning as an active process in which learners construct new knowledge based on previous knowledge. According to Vygotsky (1930/1978), students learn best when engaged in social interaction in which they learn from the teacher and from each other. 
What are the tenets of constructivism? I have derived three basic tenets of constructivism that relate to reading instruction: learning is active, learning is social and learning is based on past experience.

Learning is active. Constructivism portrays the reader as actively building a mental image by combining new information from the text with past knowledge (J. R. Anderson, 1983; Johnson-Laird, 1983; Kintsch, 1974). Since the constructivist theory claims that knowledge is active and constructed by the learner, learning depends to a significant extent on the learner's internal drive to understand and promote the learning process (Vygotsky, 1930/1978). In the early 1970s cognitive approaches to reading moved from focusing on words and sentences to looking at texts as researchers examined brain processes in student memory and understanding. Some psychologists argue for the constructivist ideas that students, not books, carry meaning, and students construct meaning as they go. Von Glaserfeld (1995) argued that "From the constructivist perspective, learning is not a stimulus-response phenomenon. It requires self-regulation and the building of conceptual structures through reflection and abstraction" (p. 14).

Learning is social. Vygotsky (1930/1978) emphasized the social contexts of learning and the idea that knowledge is mutually built and constructed socially (Horowitz et al., 2005; Rust, O'Donovan, \& Price, 2005). The student constructs knowledge from experience, which makes knowledge unique to each individual (Vygotsky, 1962/1986). The role of a participant that is considered more knowledgeable is able to support the student through the Zone of Proximal Development (ZPD; Vygotsky, 1930/1978). 
According to constructivism, the social climate of learning is important and learners refine their own meanings to help others find meaning.

Vygotsky (1930/1978) suggested that students accomplish more difficult learning in collaboration with people who are more advanced, such as peers and teachers. When student and teacher participate in learning, it reinforces teacher scaffolding during difficult tasks and the teachers slowly withdraw their support so that students are eventually able to perform the task independently. Constructivist learning environments encourage learners to gather information, use the information, analyze, and reflect on the information to enhance comprehension.

Vygotsky (1930/1978) viewed reading and writing as social processes that include the community of learners in the classroom, which requires creating a culture for learning, communicating, and sharing experiences with others. Therefore, in constructivist classrooms, where the teacher acts as a facilitator and a guide, learners are accountable for their own learning. The learning requires student participation, taking place in a meaningful context and the learning often occurs in the real world (Vygotsky, 1930/1978).

Learning is based on past experience. Constructivist perspectives suggest that students use their knowledge of the world to construct their own meaning (Bransford, Barclay, \& Franks, 1972). Constructivist theorists argue that the learner is not a passive participant in the classroom as in behaviorist theory, but rather that knowledge is real and the learner is an active participant in constructing knowledge (Labinowicz, 1980). In the constructivist approach to learning, the learner's active participation is constructed 
through the process of social interaction. In constructivist-influenced pedagogies, learners are also involved in decisions, in selection of materials, and in the process of learning (Benson, 2001).

Similar to the constructivist theory is Kelly's (1955) theory of personal constructs, which proposes that learning occurs through our own experiences. As we engage in a new experience, the patterns of old experience occur and we create new ideas as we work through the learning process. For example, as a teacher models a reading strategy, the learner practices the reading strategy with the teacher through guided practice. Next the student practices the reading strategy with a peer during independent learning. As the student gains knowledge about the strategy, the student is able to tutor the reading strategy to another peer. The student learns a new strategy, old strategies may occur, and the student creates new thinking about the strategy with reading. Learners create their own way of thinking through a process, in which modeling, guiding, and independent learning occur.

According to researchers Rumelhart (1977) and Stanovich (1990), readers are able to construct meaning using prior knowledge and information in the text as described in the constructivist approach to learning. Each student brings knowledge, opinions, and experiences to the learning. Tompkins (2003) argued that readers use prior knowledge and textual features in an interactive manner as well as use word identification skills and comprehension strategies. 


\section{Review of the Theories of the Teacher's Role in Reading Comprehension}

Based on the three tenets above, the teacher and other students play an active role in constructing meaning and promoting reading comprehension. In this section, I write about Vygotsky's (1930/1978) ZPD; Pearson and Gallagher's (1983) Gradual Release of Responsibility; Wood, Bruner, and Ross' (1976) scaffolding; and Palincsar and Brown's (1984) reciprocal teaching. Each of these theories of how teachers and students should interact over text are research-based components of effective reading instruction, especially instruction that is based on the tenets that undergird constructivism.

\section{Vygotsky's Theory on Development and Learning Perspective-ZPD}

ZPD is a concept that refers to the difference between a learner's ability to perform a task independently versus with guidance from the teacher (Vygotsky, 1930/1978). Once the teacher teaches the concept of reading strategy in comprehension, students practice the concept with the assistance of the teacher. The teacher guides the students through the reading strategy until the student learns the strategy and is able to work independently. The concept ZPD is the zone in which the student works independently versus guided practice with the teacher.

Vygotsky (1930/1978) said learning does not occur in isolation and independently, rather learning occurs as students interact with experts in problem-solving situations. The social interaction does not always lead to learning. A. L. Brown, Palincsar, and Armbruster (1984) said "development progresses from social to individual cognitive processing” (p. 285) from social speech to inner speech. Vygotsky's (1978) theory of development and learning has an implication for instruction. Learning creates 
development as a student progresses through various cognitive zones of development. The zone of actual development is the level of independence where a student progresses without assistance.

The ZPD describes what a student is able to do with help from an adult or peer who is more capable. The ZPD offers an opportunity to teach and learn. Teaching in the ZPD requires an expert to model how to complete a task and provide assistance to the student. The expert gradually removes support and the student is able to complete the task independently.

Vygotsky (1930/1978) noted that the best teaching and learning happens in the student's ZPD. The ZPD occurs when the student learns with the help of a more capable individual such as teacher, who acts as a cognitive coach. An example would be supporting struggling readers while they read a novel. The cognitive coach provides modeling from a more capable individual (Lyons, 2003). Routman (2003) stressed the urgency in teaching reading. As students work in the ZPD, there is an opportunity for the cognitive coach to make the best use of time in every moment of the teaching day. Students are not aware of instruction, but learn from the guidance of the instructional support.

Tharp and Gallimore (1988) argued that there are four stages of reciprocal influence of students and their environment in a social context. Guided instructional support requires less assistance as the student learner becomes more independent. In stage one, performance is assisted by instructional support. An example would be when a student has very limited understanding of the task. The teacher, more capable peer, or 
parent would model expectations and the student's response may be imitative (Wertsch, 1978). The student learns gradually as the stages of the activity are interrelated to each other. In stage one, students learn much like a cognitive apprenticeship model where the teacher models learning behaviors to the apprentice (student) and the apprentice attempts to imitate the behaviors. Learning is differentiated for the student during the apprenticeship according to student individual knowledge and the understanding of the task is eventually transmitted to another learner. For example, a meat cutter demonstrates how to cut meat to another meat cutter with little experience. The meat cutter who has little experience gains the experience through modeling, guiding, and eventually becomes part of the apprenticeship (Bandura, 1977).

\section{Gradual Release of Responsibility}

What happens in the ZPD can also be characterized as the gradual release of responsibility from the teacher to the student. The gradual release of responsibility is defined as instruction that shifts from teacher-as-model, to teacher and student responsibility, to independent student practice and learner achievement (Pearson \& Gallagher, 1983). During the gradual release of responsibility, teachers go through a structured process, taking responsibility within the learning process. The explicit modeling and instruction to guided practice and independence occurs through an active construction of meaning. This is different from what happens when students learn in isolation (Piaget, 1977). This process of gradual release of responsibility shifts from teacher modeling to independent practice by the student and gradually, the learner applies the knowledge to a new situation (Pearson \& Gallagher, 1983). The gradual model moves 
from the teacher assuming the responsibility for learning to students taking on the responsibility (Duke \& Pearson, 2002). The gradual release may take place over a week, month, or year. Graves and Fitzgerald (2003) argued that through this process, teachers gradually do less work and students gradually assume responsibility for their own learning. Through the process of teachers releasing responsibility to students, students become independent learners. As learners experience situations that conflict with their way of thinking, unevenness may occur. Students may experience a different idea through collaboration, working with peers, and guided practice from the teacher. Learners must move between new and old thinking to gain understanding. Learners make sense of new knowledge by associating it with previous knowledge (Pearson \& Gallagher, 1983).

Gersten and Baker (2000) argued that students who work in isolation and struggle with learning benefit from guided practice during the process of gradual release model. Fisher and Frey's (2007) gradual release model defined the specific stages in detail. Initially, there is a two-way interaction where student and teacher build an understanding of the instruction between the teacher and student. At the start of the lesson, the teacher provides direct instruction. Next, the teacher engages in guided instruction as teacher and student work together. Finally, the student engages in independent practice and takes full responsibility for the learning. At the end of the model, teacher and student engage in collaborative learning as the teacher moves among students and provides support. This model represents gradual release of responsibility in all models of instruction (see Figure 1). 
In this gradual release of responsibility model, the focus lesson is where the modeling occurs for the student. In the first phase, teachers state a clear purpose and model their own thinking in relation to the identified problem of learning. The next phase of instruction occurs during guided instruction. Tomlinson (2001) stressed differentiation, which is where students work one-on-one or in small groups of four to six students based on skill, practice, or understanding and the teacher meets with the student group to guide students during instruction. In the next phase of reciprocal teaching, learning occurs when students are able to work independently reading a piece of text in common and are able to discuss the text using reading comprehension strategies.

The gradual release of responsibility model of instruction

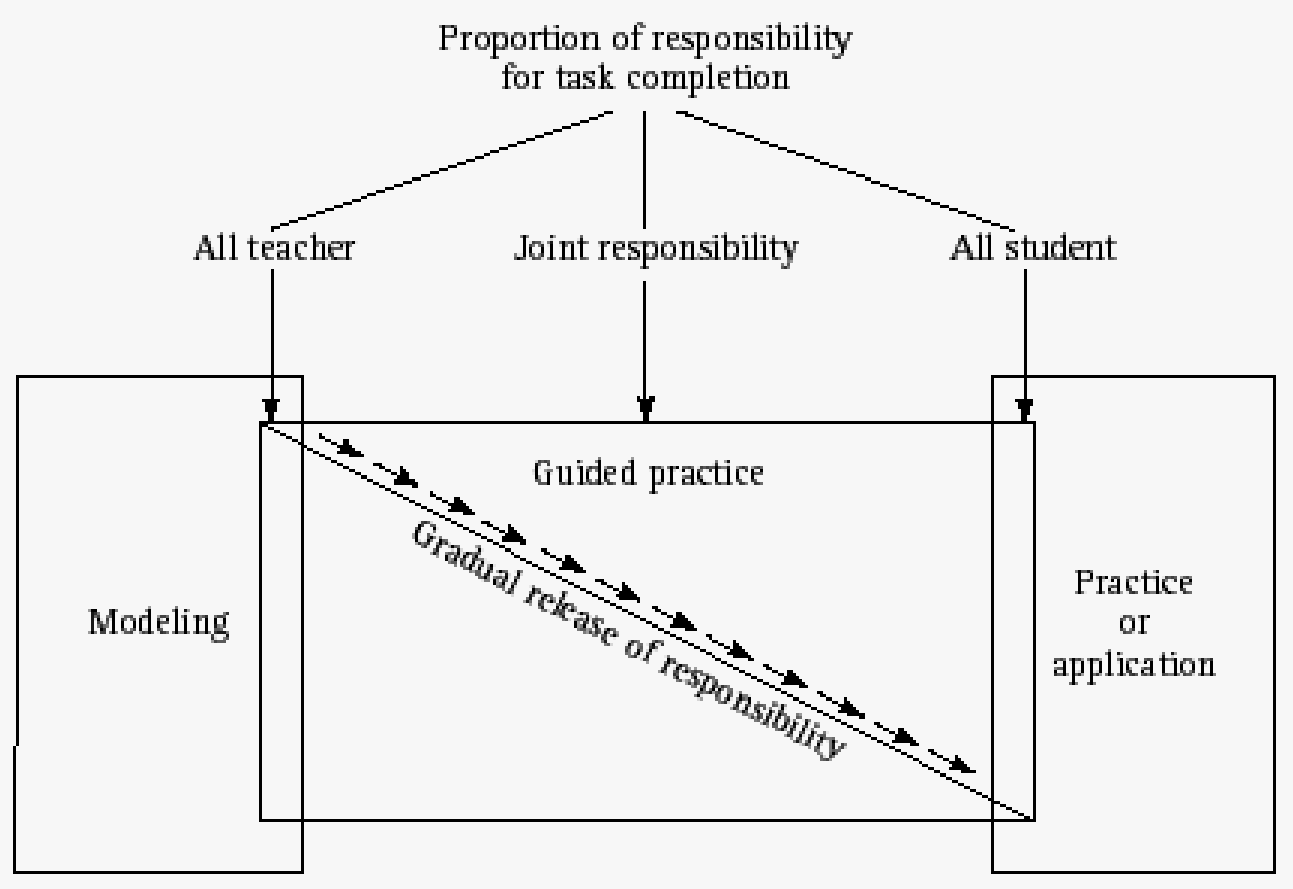

Figure 14.1 Gradual release of responsibility model (Pearson \& Gallagher 1983, after Campione, 1981).

Figure 1. Graduate release of responsibility model. Source: Pearson and Gallagher (1983). 


\section{Scaffolding}

Scaffolding is one of the basic strategies that can be used in the ZPD as teachers foster the gradual release of responsibility. Scaffolding is a process in which students receive support until they are able to become independent learners (Wood et al., 1976; Rosenshine \& Meister, 1995). Scaffolding is structured small and multiple-step instruction between teacher and student that helps students achieve their goals. Scaffolding instruction is a process of assistance by a teacher or peer to support learning (Wood et al., 1976). Students are taught a skill, the skill is modeled and another skill is added to the instruction that scaffolds the instruction. If the student is not able to learn a concept or task in reading comprehension, the teacher or another student is able to assist by modeling the strategy. As the student is able to master the task or concept, the teacher takes away the scaffold or assistance. The student is able to work independently.

The benefit of scaffolding instruction is that it actively engages teacher and student (Ellis, Worthington, \& Larkin 1994). The term scaffold is a supporting framework that a teacher uses with students in order to enhance learning process (Wood et al., 1976, p. 90). Through the supported framework of scaffolding, students have the opportunity to become independent learners.

\section{Reciprocal Teaching}

Palincsar, Ogle, Jones, and Carr (1986) defined reciprocal teaching as instruction that takes place when teachers and students are engaged in dialogue about sections of text. The purpose is to use conversation in guided reading. Students work with adults and 
other students to understand what they read in the text. Some of the reading strategies used are summarizing, clarifying, predicting, and asking questions. Palincsar and Brown (1984) conducted many research studies on the effectiveness of reciprocal teaching. Students passed comprehension tests and change took place in the student dialogue that occurred each day. In addition, fewer behavior problems occurred in the reciprocal teaching groups in comparison to the non-reciprocal teaching groups. Another positive student outcome is the ability to write summaries, predict test questions, and become problem solvers in reading text.

\section{Review of Research on the Daily 5 and CAFÉ Reading Framework}

A few recent studies have contributed to our understanding of how Daily 5 works to promote meaningful literacy. The Daily 5 book was published in 2006 and 2014, along with workshops by "the sisters," Boushey and Moser. The Daily 5 book goal is to foster literacy independence in the elementary grades (Boushey \& Moser, 2006). The CAFÉ Book was published in 2009, along with workshops by Boushey and Moser. The goal of The CAFÉ Book is to support teacher practice in literacy assessment and instruction (Boushey \& Moser, 2009). Gail Boushey and Joan Moser are sisters that have a combined experience of more than 40 years in elementary classrooms. Their experience has led to the development of The Daily 5 and CAFÉ. This section details some of the ways other researchers have studied the problem of literacy and what they have learned from the Daily 5 literacy framework. All of these ideas are important because many of them integrate with each other and help with understanding the development of the Daily 
5 framework (read to self, read to others, listen to reading, vocabulary work, and work on writing).

The first study and research looks at the effects of Daily 5 on classroom literacy instruction. This qualitative study by LaShomb (2011) studied the effects of the Daily 5 on classroom literacy instruction. The qualitative study took six weeks and the data methods consisted of interviews and classroom observations. The study involved five general education teachers who used the Daily 5 literacy approach in second grade classrooms. The schools were located in suburban settings near a large city (LaShomb, 2011). The central research question looked at the effects of the Daily 5 on classroom instruction (LaShomb, 2011). The researcher found that one of the outcomes from the action research was elimination of behavior problems. Through modeling a process of reading expectations, students are able to become independent readers. In his findings, students were able to use routines and systems to work on their own without teacherdirected instruction. As students worked independently, observed findings reported that teachers were able to work with individual students and small groups of students. As a result of Daily 5 framework, the researcher reported that students were able to develop reading stamina more readily (LaShomb, 2011). Reading stamina is described as student reading books for long periods of time. The goal is to increase the amount of reading time (Boushey \& Moser, 2006).

In this action-research study about the effects of the Daily 5 on classroom literacy instruction, LaShomb (2011) used a constant comparison method for a full analysis of research data. The constant comparison model begins with the raw data in comparison 
with the hypothesis question. Several themes, similarities, and differences began to emerge (LaShomb, 2011). The themes that emerged from the study indicate Daily 5 creates student independence and student ownership of their own learning. The LaShomb study reported that the approach of Daily 5 offers a strong and balanced framework for instruction in reading and writing development in students. The study also reported that the Daily 5 not only allows students to become independent learners, but this model helps in other subjects and provides a framework for students to become lifelong learners (LaShomb, 2011). Further recommendations from this study suggest a comparative analysis of a centers-based approach to learning pedagogy and the Daily 5 framework. LaShomb would like to conduct further interviews with five classrooms using the centers approach and five classrooms using the Daily 5 approach to learning. Another research suggestion by LaShomb was to observe implementation of Daily 5 at the beginning of the school year in comparison with students who have never used the structure. Students who go through the process of learning reading behaviors in the Daily 5 framework at the start of school are able to read and write for long periods of uninterrupted time.

In another Daily 5 action research study, researcher Cilia-Duncan (2008)

observed the Daily 5 framework in a classroom and argued that this framework may create student engagement and independence in literacy. The researcher studied why the Daily 5 seemed to be an effective framework for managing a literacy block. This framework allows teachers time to work with students in small groups and individually. In this study, data collection included observations, interviews, surveys, journals, and conferences. The research questions looked at engagement of students using the Daily 5 
framework and asked questions about whether providing student choice increases reading motivation and whether the purpose and urgency in Daily 5 framework have a positive impact on student reading and writing. The research used data from observations, surveys, scores, writing journals, and individual student conferences (Cilia-Duncan, 2008).

The results from this action research project demonstrated positive impact of Daily 5 on student achievement. Cilia-Duncan (2008) provided data results from reading comprehension testing. Twenty-one students in this classroom study received Daily 5 instruction. Results from this study indicated that Daily 5 increased reading fluency. English language learners and Title 1 students increased in reading achievement. CiliaDuncan argued that the Daily 5 pedagogy enables the positive effect of small groups and conferences (Cilia-Duncan, 2008). Taylor et al. (2003) supported a student-driven framework that allows many opportunities for teachers working with small group conferences. Cilia-Duncan also endorsed Daily 5 pedagogy for use in elementary classrooms during reading and writing instruction.

As a result of the studies on Daily 5 reading framework, some researchers claim that the student-driven Daily 5 framework leads to independent learning (Cilia-Duncan, 2008). Other researchers claim that as student behaviors improve, achievement increases. As students increase reading time due to reading behavior goals, they also develop reading stamina. This is a result of using the Daily 5 (Cilia-Duncan, 2008). As a result of independent literacy on-task time, outcomes in other academic subjects increase also. 
Some researchers support the gradual release of responsibility from teachers to students as practiced in Daily 5.

In an examination of Daily 5 and CAFÉ pedagogy in a school district's professional development program, Peterson (2011) examined whether the books on the Daily 5 and CAFÉ are good resources for a school district to use for enriching teacher professional development and instruction. With the pressure to advance student test results in reading, teachers seek ways to improve reading instruction. Therefore, Peterson argued that it is important to explore and investigate Daily 5 and CAFÉ pedagogy to improve teaching.

One of the purposes of Peterson's (2011) study was to look at differences that distinguish the Daily 5 from other reading models. Some of the differences the study found in this comparison consist of a teacher's ability to manage the entire literacy block using the Daily 5 pedagogy. The literacy block is a scheduled amount of time in which students work on reading and writing. In the typical fourth grade classroom, literacy consists of a basal reader adopted by the district curriculum. Students read from the textbook, answer questions independently, and may work in guided reading groups. Some differences between Daily 5 and other methods of managing reading instruction are the clear expectations of the Daily 5 framework. Students are able to work in the Daily 5 framework for long periods of time in contrast to short reading groups in a typical classroom setting. In contrast, Daily 5 and CAFÉ include a short focused lesson on a reading strategy. The teacher models the reading strategy and students practice using the reading strategy during reading and writing. Next students continue strategy practice 
during Daily 5 rotations (read to self, read to others, listen to reading, work on writing and vocabulary work). As students engage in practice, they are able to build reading and writing stamina. This ensures longer periods of time focused on reading and writing independently (Boushey \& Moser, 2006). The structure of Daily 5 in general allows teachers to use gradual release of responsibility with an outcome of independence in literacy. At the beginning of a new school year, teachers are able to model clear, expected reading behaviors using the Daily 5 . The clearly defined instructional routines help to accelerate reading pedagogy (Peterson, 2011).

Peterson's (2011) study focused on an evaluation from teachers who read and utilized the Daily 5 and CAFÉ. A survey was administered to teachers to collect data from the teachers who use the Daily 5 and CAFÉ pedagogy by the researcher (Peterson, 2011). Some of the questions included: which components do you use in the Daily 5, which components are the most important in the Daily 5, and did you experience negative effects in the use of the Daily 5? The conclusion from surveys, questions, and interviews determined that teachers experienced benefits from reading and using the strategies in the books. Some of the drawbacks included the time it takes teachers to read the books, process the information, and implement the pedagogy in the classroom. In the conclusion, Peterson recommended using the books on the Daily 5 and CAFÉ in her school district's professional development program.

As students participate in the Daily 5 and CAFÉ framework, students self-select a variety of books to meet their reading needs. Next, teachers demonstrate and model fluent reading and writing so that students learn how to construct meaning from print. The 
transaction occurs as students choose books, interact with the text, and write for personal and authentic reasons. Since instruction during Daily 5 and CAFÉ goal is transaction with text and constructing meaning, best practices from reading research are substantiated in interactive read-aloud, guided reading, shared writing, independent reading and writing. All of these best practices are part of the Daily 5 and CAFÉ and emphasize reader transaction with text.

Boushey and Moser (2014) argued that if learning is important to the individual student, the individual student would be inspired to learn and gain new knowledge by participation in a literacy framework. The literacy framework may be inspirational as students are able to select books, arrangements in the classroom, and one-on-one conferences with the teacher. Students become builders of their own cognitive tools. Knowledge and the world is constructed and constantly reconstructed through personal experiences. As students participate in the Daily 5 literacy framework, they build new knowledge through participation and experience in the five tasks. The five tasks are read to self, read to others, listen to reading, writing, and vocabulary work (Boushey \& Moser, 2014).

Elementary teachers in the Osceola School District and/or Somerset School District were requested to take a survey about use of books on Daily 5 and CAFÉ in professional development programs in both schools (Peterson, 2011). This program evaluation examines whether the books on Daily 5 and CAFÉ would be good resources for the Somerset School District to utilize for the purpose of enriching teacher professional development and instruction. In an examination of the books on Daily 5 and 
CAFÉ in a school district's professional development program, Peterson conducted a survey that consisted of data collected from 45 elementary school teachers who may or may not have read the books, The Daily 5 (Boushey \& Moser, 2006) and The CAFÉ Book (Boushey \& Moser, 2009). The survey's purpose was to determine if teachers were utilizing components of either The Daily 5 or The CAFÉ Book (Peterson, 2011).

Early research suggests that in comparison to other reading programs that are scripted, students in classes that use Daily 5 reading pedagogy show more positive results in intentional reading. Students use substantial amounts of time to read and write, teachers help students to monitor literacy goals, and students became independent readers. As a result of professional development, research, and book studies of the Daily 5 and CAFÉ, practitioners are able to implement Daily 5 pedagogy as an instructional approach and technique that improve student reading development (Peterson, 2011).

While there is research on the Daily 5 and CAFÉ literacy framework, there is very little theoretical, empirical, or practitioner research that specifically explores the impact of Daily 5 and CAFÉ literacy framework on reading comprehension for struggling students.

\section{Summary}

With increasing pressure to improve student test results in reading, teachers need evidence for effective reading pedagogies. As a result, teachers continue to explore and investigate reading programs and methods to increase reading fluency and comprehension. Researchers investigate techniques to improve the understanding of instruction and professional development practices. While more research is clearly 
needed, early research suggests that the use of Daily 5 and CAFÉ framework are effective in improving student reading comprehension.

Boushey and Moser (2012), authors of the Daily 5 and CAFÉ framework, argued that our educational system is heavily focused on purchasing programs, materials, and methods that may be problematic to teach reading comprehension. Daily 5 reading and writing pedagogy provides a framework for conferring with students, a system to record growth in reading comprehension, and promotes student independence in literacy (Boushey \& Moser, 2012). The CAFÉ purpose is to record student reading and writing strengths and goals, establish flexible student groups with focus on reading strategy, and assist students during reading strategy lessons (Boushey \& Moser, 2012). With the implementation of Common Core Standards and Smarter Balanced Testing in literacy, teachers continue to question how to implement a reading framework that fits the needs of all students to improve reading comprehension, especially in struggling readers.

This study supports how Daily 5 and CAFÉ framework impact struggling readers in reading comprehension. Chapter 3 addresses proposed methodology for this study. This chapter begins with an introduction, research questions and method, setting, participant selection, participant sampling, data collection, instruments and measures, role of the researcher, data collection and analysis, and limitations. 


\section{CHAPTER 3}

METHOD

\section{Introduction}

Chapter 3 provides details of the research design and methodology that were used in this qualitative case study. The purpose of this case study is to explore the impact of a reading framework on fourth grade struggling students' reading comprehension, attitudes and engagement. The problem is that struggling readers are not making progress in reading comprehension (Allington, 2012). Impact is defined as how a reading framework affects students who struggle with reading comprehension. This study looks at how six students in a fourth grade classroom engage in a literacy framework that uses the Daily 5 (read to self, read to others, listen to reading, writing, and vocabulary work) and CAFÉ (an acronym for comprehension, accuracy, fluency, and expand vocabulary (Boushey \& Moser, 2006). The criteria for selection of six students were based on reading comprehension scores, gender, age, and ethnicity. Chapter 3 is organized into the following sections: (a) introduction-purpose and problem of the study (b) research questions and method, (c) setting and participants, (d) procedures, (e) data collection (f) role of the researcher, and (g) data collection and analysis.

\section{Research Questions and Method-Type: Case Study Approach}

Qualitative research is a systemic approach to understanding qualities, or the essential nature, of a phenomenon within a particular context. (Brantlinger, Jimenez, Klingner, Pugach, \& Richardson, 2005, p. 195)

Creswell (1998) defined qualitative research as an 
inquiry process of understanding based on distinct methodological traditions of inquiry that explore a social or human problem. The researcher builds a complex, holistic picture, analyzes words, reports detailed views of informants, and conducts the study in a natural setting. (p. 15)

Qualitative research is appropriate if the researcher wants to explore the views of participants, as I did in this case study (Creswell, 2002). In this qualitative case study, it is appropriate to focus on student performance in reading comprehension within small group behavior. The case study also investigates a reading framework in depth and in real-world context such as the classroom. For example, this case study relies on multiple sources of evidence with triangulating evidence, reporting any personal bias by the researcher (Yin, 2014). The project used a qualitative case study, stating the study steps and procedures in detail to improve validity. This method allowed the researcher to generate a description of an event or understand a specific setting or environment (Bogdan \& Biklen, 2003).

I chose a case study approach due to the purpose and goals of the research, which were to describe the effects of a specific literacy framework in a fourth grade classroom (Yin, 2014). Qualitative research involves the use of words instead of numbers to arrive at conclusions. In case study research, the researcher is able to study in natural settings, attempting to make sense of, or interpret phenomenon that research subjects bring to the study. In this case, I looked at students in my classroom that participate in a literacy framework (Denzin \& Lincoln, 1994).

The qualitative design of the project allowed me to collect lived experiences in the classroom using interviews, surveys, questionnaire, Draw-a-Reader, an achievement test, and reflection journals. Since this study was conducted in my classroom with 
students I teach, I was able to document the lived experiences of the students. This field study approach is a case study, which was bounded by the physical setting, my classroom and by time, 10 weeks (Creswell, 2003). Data collection was limited to one hour each day, and occurred during reading framework rotations. This single, exploratory case study provides a situation in which a reading framework or intervention being evaluated has no clear set of outcomes. The classroom interactions observed and interpreted can be easily applied to and tested in other classrooms (Yin, 2003). The six students chosen to participate in this study had reading comprehension scores below grade level. I chose students who struggled with reading comprehension to assess how a reading framework impacts struggling readers to improve their reading comprehension. The problem is that students score below grade level in reading comprehension and the purpose of this study is to improve reading comprehension scores. The study is guided by the following research questions:

1. How do students perceive their experience in Daily 5 and CAFÉ strategies framework?

2. How do struggling students respond to specific Daily 5 and CAFÉ reading framework?

3. What are struggling students' attitudes toward reading and themselves as readers?

4. What kind of growth in reading comprehension did the struggling students have over one year?

This study covered 10 weeks during the school year. The developmental reading assessment scores were compared at the beginning of the school year and at the end of the school year to measure growth in reading comprehension. The developmental reading assessment is administered individually to students to measure accuracy, fluency, and 
comprehension in September and again in June. The Daily 5 and CAFÉ instruction begins in September and concludes in June.

\section{Setting}

The study took place at a public elementary school that serves students in kindergarten through fifth grade. The total school population for the school is more than 600 students. The school is located in a suburban area with a population of 100,000 residents. According to a state report card for elementary schools, the school received an exemplary award for academic achievement in math and reading for the years 2002-2011. Attendance at the school is near 97\%, and parent involvement with the school is above average. Most students live in rural environments and travel to school by bus transportation. The school was built 14 years ago, and $50 \%$ of teachers at the school have a master's degree. Three teachers at the school have attained National Board Certification.

Seventy-one percent of the students qualify for free and reduced breakfast and lunch programs; therefore all students at the school receive free breakfast and lunch each day. Twenty-five percent of the students are in English as a Second Language Program. As a result of free and reduced lunch percentages, the school qualifies for School-Wide Title One Reading Programs. Title One Reading program serves grades kindergarten through fifth grade. Special Education students are 5\% of the school population. The school also has a behavior support classroom. Library, Physical Education, and Music are reduced to one class a week. Most classrooms at grades 3-5 have more than 30 students. 
Students at this school participate in a Behavior Support Program, Right Brain Art Initiative, Restorative Justice Program, and Honor Assemblies each month.

\section{Participants: Selection}

The participant pool for this study consisted of six fourth grade students from the same classroom that struggle with reading comprehension. This section explains participant selection and offers a description, their progress, my impression of them, and their families in detail. In Institutional Review Board approval, their names were changed to protect their anonymity. Specifically, the criteria used to select the participants were that they must struggle with reading comprehension at the fourth grade level. Student reading comprehension scores for each participant were well below grade level. Six individuals were chosen and each parent or guardian of the students signed a Letter of Informed Consent (see Appendix B), which described the purpose, activities, and potential risks and benefits for research subjects, as well as my contact information. The letter also explained that participation in the study is voluntary, and participants were able to withdraw at any time without repercussions. Each individual student signed a child assent form for ages 12 or under (Appendix A).

\section{Mollie}

As a fourth grader, Molly was the youngest participant in the study. She turned five just before kindergarten. Molly has an older sister. She lives on a farm with 20 acres. Her father works at a local hotel, and her mother does not work outside the house. Throughout the entire study and process, Mollie talked about her chickens, sheep, cows, and gathering eggs. During the time of the inquiry, her mother enrolled in a community 
college in our attendance area. I made a home visit during the study to talk with the parents about the permission slip and to see if they had questions.

Mollie attends Title One reading classes each day and works very hard. She is well below grade level in reading. When she entered the classroom in the fall, she shared "I don't like reading." Near the end of the school year, she shared that if she has a good book, she feels like she is one of the characters in the book. Mollie is always excited about participation in the Daily 5 . She enjoys reading with other students, listening to reading on the computer, writing at the table, and meeting with the teacher during oneon-one conferences.

In the classroom, Mollie is neat and organized. She likes to tell other students what to do. Mollie is always selecting different books to read and writing many stories. Mollie is very active and likes to move during the Daily 5 rotations. During one of her interviews, she told me that she liked recess the best because she could run and play. Mollie loves school, but most of the time, she does not like to sit by herself and focus on reading comprehension.

\section{Sergio}

Sergio is the fourth child of six children. He is a Hispanic boy that speaks fluent Spanish and little English. Sergio attends English Second Language classes and enjoys the classes. Sergio also attends Title One reading class each day. He is out of the classroom for an hour a day to attend these classes. His parents are concerned about his ability to read and comprehend. Sergio's father works at a local nursery and has two jobs 
at the nursery. His mother stays at home, but sometimes works at the nursery at night. The family lives in a small apartment.

Sergio enjoys school but is disorganized and does not always pay attention. He likes to visit in the classroom with other students. He enjoys books in the classroom, but his favorite thing to do is meet with the teacher. During Daily 5, he likes to work in his vocabulary book and read with other students. Sergio also likes to move in the rotations. He enjoys sitting on a beanbag chair to read by himself. At the first parent-teacher conference in November, Sergio was barely able to decode words.

\section{Kristina}

Kristina is Asian and has two older brothers. Her mother is a nurse and her father recently retired from the Army. Her grandmother lives with the family. Kristina is very creative and loves art, projects, and writing. Kristina writes every day at the writing table and always participates in writing workshop. She enjoys Daily 5 rotations and is always excited to write. At the beginning of the year, I was very concerned with her attention to reading. She would self-select many different books in a short amount of time. Near the middle of the year, her attention span increased. Both parents expressed many times their concerns about their daughter's ability to focus on reading. Kristina enjoys art projects and draws illustrations from books.

Kristina likes to read about projects and put them together. Kristina is a very quiet and organized girl, but my concern was about her ability to comprehend what she read. During our one-on-one conferences about reading strategies, I would encourage her to read about artists. During the year, she was able to give reports in front of the classroom 
about artists. She was able to set goals and make progress. Kristina always wanted to work with others on art, sewing, and craft projects in the classroom. Her response journals entries talked about her projects in the classroom.

\section{Lance}

Lance is a good-natured, quiet boy that seems to enjoy reading. He lacks confidence in his reading and has a lot of difficulty with comprehension. He worries about making progress. He likes to set goals during one-on-one conferences. He attends Title One and enjoys working with the teacher.

Lance likes Physical Education and likes to run and play with his friends. He also likes sports. Lance would always self-select sports books during the year. He also excited to work in the Daily 5 rotations, especially if he could use the iPad. He would listen to stories about famous sports heroes and write stories about them on the computer. Lance set reading goals for himself each week. He had a reading partner that would check in with him each week.

\section{Natalia}

Natalia is from a Hispanic family of three children. Her parents own a Mexican restaurant and are not at home most of the time. Natalia is with a babysitter after school and some weekends. She speaks Spanish and English but is disorganized and tired. She likes her friends and talks a lot in class. Natalia attends Title One reading class and makes slow progress. Natalia likes to read books about fashion and cooking. At the beginning of the school year, she was well below average in reading comprehension. 
Natalia was always excited to participate in Daily 5 rotations each week. As Natalia participated in Daily 5 read to self, she would select books and select a place to read at the small couch in the room. During Daily 5 writing rotation, she would sit at the writing table and write directions about how to make a cake. Natalia's writing journal included illustrations of steps to make a cake or sew a pillow.

\section{Owen}

Owen is an African-American student that has a younger sister. Owen repeated kindergarten and struggles with reading. He is able to decode words, but has very little understanding about what he is reading. He is motivated to read, but has very few strategies to comprehend the text. He also self-selects the same books. When I interviewed him, he seemed nervous at first, maintaining little eye contact. During the end of the study, he was not nervous at all, but rather excited to share how he enjoyed reading new books. He was very quiet in the classroom and liked the room when it was quiet.

\section{Participants: Sampling}

The case study occurred over a 10-week time period from April to June. The sampling is purposeful using maximum variation (Miles \& Huberman, 1994) sampling with parameters of gender, age, low readers, and ethnicity. Maximum variation sampling is used to capture a wide range of perspectives. I choose an equal number of students based on gender, three boys and three girls. All students selected are low readers. Three students are 10 years old and three students are 9 years old. Two students are Hispanic, 
two students are Anglo-American, one student is African-American, and one student is Asian American.

One of my objectives in this inductive method of inquiry was to learn from indepth interviews. Therefore, the quality of the sample is important in comparison to the number of students. My focus was on students who struggle with reading comprehension. Although there were other students struggling with comprehension, the six students selected had the lowest achievement scores in reading comprehension. I did not choose high and middle readers due to my underlying question about how a literacy framework assists low-level students that struggle with reading comprehension.

The specific experience of the Daily 5 framework enables me to answer the research questions. I conducted individual conferences and interviews with students during Daily 5. I was able to set individual reading goals with students and collected artifacts such as reading response journals. More specifically, I was able to use triangulation because I had multiple data sources: attitude surveys, interviews, reading response journals, Draw-a-Reader, questionnaire, and achievement test scores of students who participated in the Daily 5 and CAFÉ. Reflection in my real-life classroom setting helped me create a rich description (Geertz, 1973) of the location and people involved, events, and situations in the research setting, in this case, my fourth grade classroom. The researcher's role is one of active participation as the researcher is the primary instrument for data collection (Creswell, 2002, 2003; Mertens, 1998; Tesch, 1990).

Data collection sources include interviews, reading response journals, an attitude survey, questionnaire, Draw-a-Reader, and achievement test scores. The procedures for 
data collection sources were conducted with students in my classroom as students participate in Daily 5 and CAFÉ literacy rotations. I conducted the research over 10 weeks beginning in April and ending in June. I met individually with six students each week to conduct interviews. I met with students individually to look at reading response journals. Draw-a-Reader was conducted once a week during the 10 weeks. After each interview, I reflected in a research field journal and prepared for the next interview. Reading response journals, interviews, surveys, questionnaires, and Draw-a-Reader were documented into five different notebooks. Details of the reading response journals, interviews, and Draw-a-Reader were documented in individual notebooks for each student. Written responses were recorded next to Draw-a-Reader, journals, and surveys. Reading response journals consisted of an individual student journal in which students wrote a written response about participation in each Daily 5 rotation. For example, a student participates in read to self and then the student writes about their experience in read to self. Draw-a-Reader is when a student draws a picture as a reader. Interviews were conducted as the student wrote about Draw-a-Reader.

Permission to conduct this study was obtained from my participating school district verbally. I also met with my principal to obtain permission to conduct the study in my classroom. At this time, I presented a letter (see Appendix B consent form) that was sent home to parents of the six students participating in this study with an explanation of the study and requesting permission for their children to participate. I sent out six consent forms (Appendix B) to parents of the six participants and all six student forms were signed by parents to participate. In addition to school district approval, I submitted an 
Institutional Review Board application to the Portland State University Institutional Review Board. Institutional Review Board approval was obtained prior to the collection of data so that all participants in the research are protected from potential breaches of confidentiality or other harm.

\section{Data Collection}

Yin (2009) said that a well thought out case study benefits from multiple sources of evidence, to make sure that the study is as strong as possible. Various kinds of data were collected for this case study. Interviews were scheduled at a time that was convenient for the students. The interviews took place in the classroom within the school day, with each session documented in writing. Documentation of writing guarantees accuracy of records, permitting me to focus on the students and their responses. The interview questions are included in Appendix C, and each interview lasted between 10 and 15 minutes. Prior to the interview, the student's parent signed a consent form in Appendix B permitting the session to be documented in writing verbatim for data analysis. A second interview was requested only if clarification was needed. The interviews were transcribed as they occurred. A third party was employed by the researcher to make certain of the accuracy, and to diminish potential bias in the written documentation. All involved had the opportunity to review the written record at a later date to ensure accuracy and to permit any follow-up questions or comments. In addition, I conducted Draw-a-Reader interviews with written records. Finally, documentation of student reading journals, reading attitude surveys, questionnaires and achievement tests were recorded in journals for each student. Data collection in this study took place during 
student participation in Daily 5 and CAFÉ framework. The data collection occurred weekly while students participated in the Daily 5, over the course of 10 weeks from April to May. I did not alter my ongoing classroom activities, and the student's participation in the class activities was not affected by their involvement in the project. I always conduct interviews during Daily 5 rotations as opposed to assessing them. The participants did not experience any known physical, psychological or social risks due to their participation.

\section{Instruments and Measures}

Data collection must be valid and reliable. The data collection tool measures what it says it does and reliability means that the tool is accurate and precise. I created several interview questions (see Appendix C) so I could modify or add questions. Reflection upon respondents' answers enabled me to deconstruct their experiences and identify themes. Another important component of data collection is selecting a case that is information-rich (Patton, 1990; Stake, 1995). The findings from this case are not statistical, but analytical and based on reasoning in the findings of student interviews, journals, surveys, questionnaires, Draw-a-Reader, and achievement tests. After each interview, I documented a written reflection in a research field journal. Three notebooks contain student journal responses, interview responses, attitude surveys, questionnaires, Draw-a-Reader illustrations, and achievement tests.

See Appendix E for Research Question Matrix. In the first phase, I began my data collection by scheduling an individual time with my students in the study. I gave students interview questions (see Appendix C). Each student participated in an interview for 10-15 
minutes and the interview was documented in writing. Interviews were documented in writing and reflected upon to begin analysis and record themes.

The next phase of my data collection included surveys, questionnaires, and achievement tests. Reading attitude surveys were documented in a notebook, and students were able to reflect about the survey. Responses from attitude surveys were written and analyzed in a journal by each student and teacher. Achievement tests in reading, which measured accuracy, fluency, and reading comprehension, were administered to students by the classroom teacher. The tests given in June were compared to September achievement scores. Summaries of the data collection were recorded in a journal to begin analysis and record themes.

The final phase of my data collection was the collection of artifacts that consisted of student journal response entries and Draw-a-Reader illustrations. The response questions (Appendix D) included reading comprehension questions and student reflections about how they comprehended the text. I included a student illustration of Draw-a-Reader in (Appendix F). Each of these components was used to answer my research questions about how this framework helps students with reading comprehension. I shared my findings with colleagues who are interested in implementing the Daily 5 and CAFÉ as a framework for their literacy instruction.

My data collection in this qualitative case study sought to address the research questions and provide rich evidence from multiple sources such as interviews, attitude surveys, questionnaires, Draw-a-Reader illustrations, achievement tests, and reflection journals. From the results, I sought to learn about student involvement, constructed 
knowledge, and transactions in reading comprehension practices. In the next section I discuss the role of the researcher in order to address bias.

\section{Role of the Researcher}

My case study explored a reading framework in my classroom. I have been working at my elementary school for 12 years and have implemented the Daily 5 and CAFÉ reading framework for the past 8 years. Since the research setting is in my own classroom, I collected the data as an insider observer. Insider observation is considered one of the most important and also difficult studies to conduct in qualitative research (Herrmann, 1989). The most important knowledge and experience I have is my connection to my students, certification as a reading specialist, and many years of classroom experience.

The limitations in this study are my previous knowledge and experience as a researcher. In this study, I used six different interactions with students that helped with multiple perspectives on the subject. I employed several teachers to read my interviews, attitude surveys, questionnaires, Draw-a-Reader illustrations, student journal entries, and achievement tests. I engaged in this study in my classroom over a period of time to reduce bias. Data collection of multiple sources through triangulation and analysis after each collected data source was also important to reduce bias.

\section{Data Collection and Analysis}

A carefully conducted case study has multiple sources of evidence, which makes the study as strong as possible (Yin, 2009). An important factor in the data analysis portion of a qualitative study is that I am the primary source for data collection. As a 
result, I must make every attempt to limit the impact of any bias that may exist. The direct involvement of the researcher in the data collection and analysis is one of the key challenges of qualitative research (Creswell, 2003), so steps must be taken to limit the impact. This was accomplished through member checks, wherein the study participants were allowed to review and students communicate about transcripts from the interview and statements made during data collection.

In an attempt to limit any bias in this study, students were given the opportunity to listen to the findings that the teacher recorded from their interview immediately after the interview and make any statements or clarifications that were appropriate. Additionally, attempts were made to confirm data by using multiple sources, rather than relying only on student interviews. Particularly, this involved several sources: exploring and reviewing journals with the study participants, and inviting teachers from two other fourth grade classrooms to review illustrations from Draw-a-Reader, and surveys recorded in a journal. Once the data was recorded for each research question, the data was analyzed and students were interviewed about their data responses for clarification.

The purpose is to understand the data in qualitative research and the process of dividing it into categories facilitates the understanding (Jacob, 1997). The objective of this process is to gather data and identify themes from interviews, attitude surveys, questionnaires, Draw-a-Reader illustrations, journals, and achievement tests. Each data source was reviewed with study participants and then recorded to see patterns and themes emerge (Creswell, 2003). The themes that emerged help to understand what happens in the Daily 5 reading experience (Creswell, 1998). In order to accomplish the analysis of 
data in this study, a matrix was used to record data from the four research questions. Next, I placed data from my four research questions, six data sources, and six participants into categories, and identified themes and patterns in student reading comprehension. Student responses were put in categories to create themes. This allows for categories of data to be developed from student information and are clustered together to create themes within the data. From these clusters, I sought to develop two distinct categories of data; one textural, dealing with the what in the reading framework experience, and the other structural, dealing with the how of the reading framework experience.

In this case study, the student responses to research questions involve the actual experiences of what happened to the students in a reading framework. In addition, the study explored how students learned during their reading time in the framework. Since the case study approach to qualitative research was utilized in this study, I sought to develop codes for the data through a process of reading and rereading the student's transcripts (Saldana, 2013). Through several readings of the data, I reflected on and reviewed the responses of the individual students in an attempt to create codes for similar experiences and to determine if they are textural or structural in nature, with the goal of dividing the codes into various categories. The overall purpose of the coding process to be utilized was to gain an understanding of the essence of the experience of the study participants (Creswell, 1998). From this process, I gained a meaningful understanding of the factors that went into their ability to connect to the reading, regardless of the challenges faced. The data analysis was directly connected with the research questions 
and information recorded from research sources. Next data were coded in relationship to each research question, identifying patterns found within.

\section{Limitations}

In a qualitative research inquiry, the study is not without limitations. Researcher bias refers to the preconceptions I bring to the study as a teacher in this fourth grade classroom. Research bias was minimized by triangulation of the data in which six different sources of data were utilized. Research questions consisted of four main questions. The questions allow for a thorough understanding of the inquiry. Researcher bias was minimized by member-checking and reflection on and critiques of my own assumptions (Maxwell, 2005). The fact that I may in effect be measuring the effectiveness of my own teaching is where the bias occurs. While I made every reasonable effort to anticipate potential issues in the process of conducting this study, there is still a limitation present in this project. The research was conducted using a qualitative methodology with a limited number of study participants. As a result, the responses of the six students who participated cannot be generalized to other students or to a larger population of students. The findings of this study can be used only to better understand and explain the experience of the individuals involved in the research.

\section{Summary}

The goal of this research was to understand the experiences of students who struggle with reading comprehension. In addition, I examined how a reading framework impacts struggling readers to improve their reading comprehension. The implementation of a qualitative approach is appropriate because it allows a story to be told or gives the 
ability to generate an understanding of the meaning of an experience (Patton, 1990). The use of this case study approach is appropriate for this study since each student in the study has had similar pedagogy experiences in this fourth grade classroom. I acknowledged and responded to ethical considerations in the research process, as well as followed appropriate methods of data collection and analysis to gain a deeper understanding of the experience of the students and the factors influencing their success in reading comprehension. In chapter 4 , I present the results of my analysis of the data collected. 


\section{CHAPTER 4}

\section{FINDINGS}

\section{Introduction}

The focus of this qualitative case study was to assess how a reading framework of Daily 5 (read to self, read to others, listen to reading, writing, vocabulary work), and CAFÉ (comprehension, accuracy, fluency, expand vocabulary) impacts struggling readers to improve their reading comprehension. The Daily 5 and CAFÉ is a framework that claims to provide students with opportunities to become self-sufficient learners, engage in reading and writing strategies, and use authentic literature each day (Boushey $\&$ Moser, 2006). My focus throughout the study was to explore their experiences and determine whether or not the framework of the Daily 5 and CAFÉ contributed to an impact in reading comprehension. Specifically, the research questions were concerned with how Daily 5 and CAFÉ literacy framework impacted six students in a fourth grade classroom that struggled with reading comprehension.

In support of the research questions, the data collection included interviews, reading surveys, questionnaires, illustrations, achievement tests, and reflection journals in a fourth grade classroom. These data sources were collected in an effort to determine how struggling students perceive their experience in Daily 5 and CAFÉ reading framework, how students respond to comprehension instruction, and what students' attitudes are toward reading. The findings reported in this chapter present evidence of the ways that a student likes to make choices in reading materials, set reading goals, collaborate with 
other students about reading, and movement from one station to another in the classroom environment.

\section{Analysis of Data}

Through various data collection tools, I gathered and analyzed data to answer my research questions. Data collection consisted of six individual reading attitude surveys for each student that asked students how they feel about reading. Next, interviews were conducted weekly with each participant about what happens in the Daily 5 rotations, what comprehension strategies have students learned during CAFÉ, and which comprehension strategies helped them to become a better reader. The weekly individual interviews with six students in 10 weeks totaled 60 interviews. Each interview with each individual student consisted of Daily 5 and CAFÉ questions. Six Burke questionnaires reported what students would like to do better as a reader. The Burke questionnaire is a written response to one question that explores the reader's perceptions about reading (Goodman, Watson, \& Burke, 1987). Additionally, 6 interviews about an illustration called Draw-aReader analyzed how students see their own progress in reading through an illustration. Fall and Spring developmental reading assessment test scores on the six students were recorded to determine what kind of growth in reading comprehension students made over one year.

This case study was bounded by time (10 weeks), but reading assessment tests are given in the fall and again in the spring, so those scores were also collected. Reading assessment tests measure reading comprehension growth at the end of the year. Finally, weekly journal entries of student reflections on goal setting and writing workshops were 
written to respond to specific CAFÉ reading framework strategies, such as goal setting and student choice.

Data sets used in the inquiry were obtained from a participant pool that consisted of six elementary students who were identified as struggling with reading comprehension. Students were 9 and 10 years old and attended school in one fourth grade class at a public elementary school. Students who participated in the study were Hispanic, AfricanAmerican, Asian, and Caucasian. There were three boys and three girls who participated in the study. The study occurred in the fourth grade classroom for a period of 10 weeks. Each student participant signed an assent form (Appendix A) and the parents of each student signed a Letter of Informed Consent (Appendix B).

The data analysis was incorporated in addressing the four research questions and seven survey questions. Each survey includes findings from the study and relates them to the theoretical foundations and related research studies that framed the current study. Following the answers to the sub-questions, the broader, overarching questions that undermined the study were addressed.

1. How do students perceive their experience in Daily 5 and CAFÉ strategies framework?

The following sub-questions are survey questions:

Survey question 1.1 Describe what happens to you in the Daily 5.

Survey question 1.2 What CAFÉ strategies have you learned? Which ones help you become a better reader and why?

Survey question 1.3 How do you see yourself as a reader at the beginning of the year and what is reading like now?

2. How do struggling students respond to specific Daily 5 and CAFÉ reading framework? 
The following sub-questions are survey questions:

Survey question 2.1 How do struggling students respond to specific CAFÉ reading framework strategies: goal setting, writing workshop, and student choice?

Survey question 2.2 How do struggling students respond to specific Daily 5 reading framework strategies: read to self, read to others, vocabulary, writing, and listen to reading.

3. What are struggling students' attitudes toward reading and themselves as readers?

The following sub-questions are survey questions:

Survey question 3.1 How do you feel about reading? Do you like reading?

Survey question 3.2 How do you see yourself as a reader at the beginning of the year and what is reading like now?

Survey question 3.3 How do you describe yourself as a reader?

4. What kind of growth in reading comprehension did the struggling students have over one year?

Results described in each of these questions were generated using a combination of Descriptive and In Vivo coding followed by Pattern coding for analysis (Saldana, 2013). The following sections discuss the findings, organized using the guided research questions.

\section{Presentation of Results-Interpretation of Findings}

\section{Research Question 1}

How do students perceive their experience in Daily 5 and CAFÉ reading framework?

1.1 Describe what happens to you in the Daily 5.

1.2 What CAFÉ strategies have you learned? Which ones help you become a better reader? 
This interview question elicited one of the major findings in this study. Students reported Daily 5 experiences allowed for opportunities to read many different kinds of reading materials, make choices of what they read, feel free to practice reading skills and strategies, and to have time to read each day. Students were excited to meet with the teacher for immediate feedback on reading goals. The interview data revealed all students were engaged in reading and writing.

In order to understand how students perceived their experience in Daily 5 and CAFÉ reading framework, I asked questions during the student interviews such as: "What do you like about reading and the Daily 5?" "How does the Daily 5 help you understand what you are reading?" "Describe what happens to you in the Daily 5." "How do you select your own books to participate in the Daily 5?" The six students responded with the following statements: Mollie said, "Everyone is calm and everyone is doing it." Sergio says, "In the Daily 5, all kids are in the zone." Kristina reported, "Reading during the Daily 5 helps me find new information." Lance goes on to say the Daily 5 "allows me to practice comprehension strategies such as reread." Owen was selecting books when I interviewed him about book selection. He said, "I like to read books in a series, it helps me to understand what I read." Natalia thought about the question and said "It helps me talk to another student about my reading as I do in read to others."

The comments from student interviews about how Daily 5 helped them in reading comprehension indicate that students like to self-select books and make individual choices in books. Other student comments were about collaboration and conversation with each other regarding what they are reading. Students described how the structure of 
Daily 5 helps them find new information and comprehend as they read. Finally, students were enthusiastic about comprehension of new information while participating in Daily 5.

The next data collection method is a data source called Draw-a-Reader. The students drew themselves as readers on a large blank canvas. If you think about the sentence "a picture is worth a thousand words," the pictures that students created were insightful. Students drew pictures of themselves to answer the questions: What happens to you in the Daily 5? What CAFÉ strategies have you learned? Students reflected on their drawings and answered questions about which drawings help you to become a better reader. Kristina created a drawing with colorful background in which she is reading a book and painting a picture. The book that Kristina holds is a how-to book about how to draw pictures. Next to her drawing is a rolling cart that holds several art books. In her picture, she created a bird in a tree with the words at the bottom of picture that said "Peace and Wonder."

Mrs. Duty-"Describe what happens to you in the Daily 5 and Draw-a-Reader." Kristina-"When I read I need to have a good book that I like, so I am able to like reading. My favorite books are art books so I can draw and paint. I read art books when I read to self in the Daily 5."

Mrs. Duty-"What CAFÉ strategies have you learned?"

Kristina-"I have learned how to be accurate with my reading, have become a more fluent reader, learned more art vocabulary, and can comprehend the reading more." "I practice with other students during read to others."

Mrs. Duty-"Which strategies help you become a better reader and why?"

Kristina-"When I choose the books during read to self, it helps me want to read the books. When I read the books and like them, I comprehend the book more." 
The second interview was about Sergio's Draw-a-Reader picture. Sergio is sitting in the middle of a room reading the book Big Nate. In the background of the picture is a bookshelf that has 25 books. The titles of the books are labeled on the spine of each book. While the student is looking at his drawing of Draw-a-Reader, I asked:

Mrs. Duty-"Describe what happens to you in the Daily 5."

Sergio-"In the Daily 5 I need a lot of good books that I choose. "When I read to self, it is like I am in another universe. I like to choose the books I read from the bookshelf in our classroom."

Mrs. Duty-"What CAFÉ strategies have you learned?"

Sergio-"I have learned how to work on vocabulary because my goal is to increase my vocabulary by reading many different books. I also like to work with other students on reading comprehension strategies, we practice together."

Mrs. Duty-"Which strategies help you become a better reader and why?"

Sergio-"I like to read many different books to help me comprehend in art, science, and social studies. I like to reread, think aloud, make a picture in my mind, and about what is happening in the book."

The next interview about Draw-a-Reader was with Mollie. Mollie's picture was a girl sitting in a chair and reading a book. She had a caption next to her picture that said, "I wonder how it is going to end." I interviewed Mollie about her picture:

Mrs. Duty-"Describe what happens to you in the Daily 5 and draw a picture."

Mollie-"I feel good about reading many different books in the classroom. I like to have the choice of many different books as shown in my picture. I like to read with my friends, help them, and work on technology."

Mrs. Duty-"Which strategies help you become a better reader and why?"

Mollie-"I set goals with my teacher on reading comprehension. So, in my picture, I put a bubble with I wonder how it is going to end. I like to set reading goals in accuracy, fluency, comprehension, and vocabulary."

Mrs. Duty-"Which strategies help you become a better reader and why?" 
Mollie-'I like to work on vocabulary in all my drawings of books. Maybe when I am done with this picture, I can pick another book to read and practice my fluency."

The fourth interview is with Owen about his Draw-a-Reader picture. Owen's picture shows him running to get his wagon of books. The cart is so full that books are falling out of the wagon. He is holding a book in his arms and running next to a tree and his dog is standing on top of a stack of books.

Mrs. Duty-"Describe what happens to you in the Daily 5 and draw a picture."

Owen-"I like to pick my own books to read. I like to work together with other people in my classroom. I like to move from one thing to another to read. It is fun to read."

Mrs. Duty-"What CAFÉ strategies have you learned?"

Owen-"'Oh, I have learned how to work on vocabulary in all the books I read in this picture. I practice my reading all the time when I read all these books that you see."

Mrs. Duty_"Which strategies help you become and better reader and why?"

Owen-"All of the strategies help me become a better reader."

Mrs. Duty-"Can you tell me any more about the reading strategies that help you become a better reader?"

Owen-"Reading lots of books and helping other students helps me read better. I practice reading a lot and in this picture my dog is listening to me read."

The fifth interview was with Lance; his picture was in the classroom sitting on a beanbag chair. He has a bookshelf behind him with 40 books in it. He drew his eyes huge and he is reading a book.

Mrs. Duty-"Describe what happens to you in the Daily 5 and Draw-a-Reader."

Lance-"When I am in the Daily 5, I sit in a chair that makes me feel comfortable. All my friends are reading and we work together. The books that I drew in the picture are books that we all like, we like to practice reading. We have so many books in our room and we read all day long." 
Mrs. Duty-"What strategies help you become a better reader and why?"

Lance-"I like when you teach us a strategy and then we practice it. My favorite strategies to practice are fluency and comprehension."

Mrs. Duty-"What CAFÉ strategy helps you?"

Lance-"Comprehension. When I work on comprehension, then I know what I am reading. Then I can read more books about one subject. I understand what I read. I connect the books with other books. I also like to look for new books."

Lastly, I interviewed Natalia. Natalia's picture has very bold colors. She drew a picture of herself holding a book about the Oregon Trail. Behind her were many different colors and at the top of the page were many different books. There were 16 book titles on the spines of the books. The titles of the books were about many different subjects we were studying in the classroom.

Mrs. Duty-"Describe what happens to you in the Daily 5 and Draw-a-Reader."

Natalia-"I read a lot of books and I learn about all different subjects because I read all the time. I am holding a book about the Oregon Trail and I love to read about the pioneers. When I read in the Daily 5, I feel free to read the books that I want to read. It is so cool. I read all the time and most of the day."

Mrs. Duty-"What CAFÉ strategies have you learned?"

Natalia-"I have learned all the strategies; they help me with my reading every day. If I need to practice a strategy, I work with one of my friends in the class and we practice our strategies."

Mrs. Duty-"What CAFÉ strategies help you become a better reader?"

Natalia-"The CAFÉ strategies that help me become a better reader are reading a lot to increase my accuracy and fluency. This will also help my comprehension. My reading goals also help me. I like it when Mrs. Duty talks to me about my reading goals."

As I conducted the interviews about Draw-a-Reader, students were excited to share stories about their pictures. The dialogue about their individual picture made it apparent that students were much more relaxed to share their feelings about Daily 5 
reading framework and CAFÉ strategies. The arts allow opportunity to create authentic avenues for learning (Cushman \& Emmons, 2002). In the data collection for my research, the arts present an interrelated conceptual bond of words, thoughts and pictures. Here I return to the research survey questions that guided this study. Describe what happens to you in the Daily 5? Which CAFÉ strategies have you learned? Which ones make you a better reader? As a result of this analyzed Draw-a-Reader data, I recommend the arts as an avenue to reach multiple learning styles.

The next source of data was student reflection journals for how students perceive their experience in Daily 5 and CAFÉ strategies framework. Students began to keep a record of their work. This takes the form of a journal. Reflective practice can be supported in the classroom by creating opportunities that allow students to think about their learning (Silver, Strong, \& Perini, 2001). Reflective journals allow students to practice their writing skills in an open-ended format that encourages the same thought process that is used in analytical writing (Zemelman, Daniels, \& Hyde, 1993). Students used reflection journals at the end of Daily 5 rotations and CAFÉ strategy instruction each day in the classroom. Students shared their writing with other students in the classroom at the end of the writing session. Students also wrote about what happens to them in the Daily 5 in the survey questions, what CAFÉ strategies they have learned, and which ones help them become a better reader and why. Table 1 outlines the results of question number one. The themes that emerged with reflection journals were choice, goals, active participation, and collaboration. 


\section{Table 1}

\section{Question \#1-Journal Response for CAFÉ Strategies, Reading, and Writing Goals}

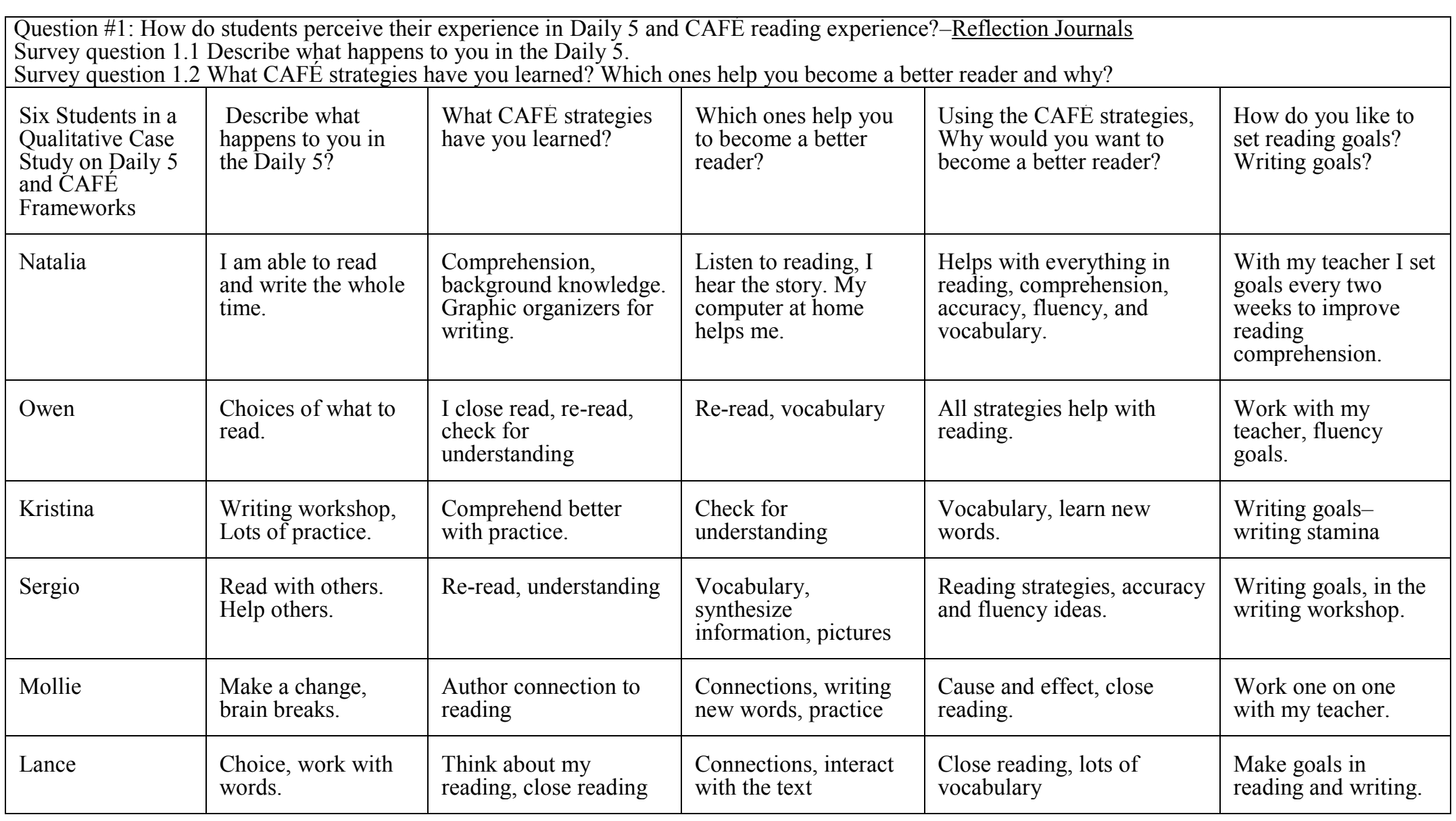


The data from journal responses in research question 1 indicated that students like to make choices in what they read. Journal responses indicate that Daily 5 rotations and CAFÉ instruction help students practice reading skills and strategies. Some of the written responses about goal setting were in reading and writing. Students liked to set goals and work with the teacher. During rotations, students wrote about how reading with other students, making changes in Daily 5 elements, and reading practice helped them become a better reader.

\section{Research Question 2}

How do students respond to the comprehension strategies taught in the Daily 5 and CAFÉ reading frameworks?

2.1 How do struggling students respond to specific CAFÉ reading framework strategies: goal setting, writing workshop, and student choice?

2.2 How do struggling students respond to specific Daily 5 reading framework strategies: read to self, read to others, vocabulary, writing, and listen to reading?

Data sources included interviews and reflection journals. Reflection journals responses were about goal setting and writing workshop. Figure 2 describes the data from question two and the survey questions.

Daily 5 relates to CAFÉ. What is taught comes from CAFÉ, an acronym for Comprehension, Accuracy, Fluency, and Expanding Vocabulary. The CAFÉ "menu" has been developed to help students understand and learn the strategies successful readers use. Students set goals with the teacher and the goals are placed on classroom display boards. The goals then form the teaching basis for individual conferences, small group, 


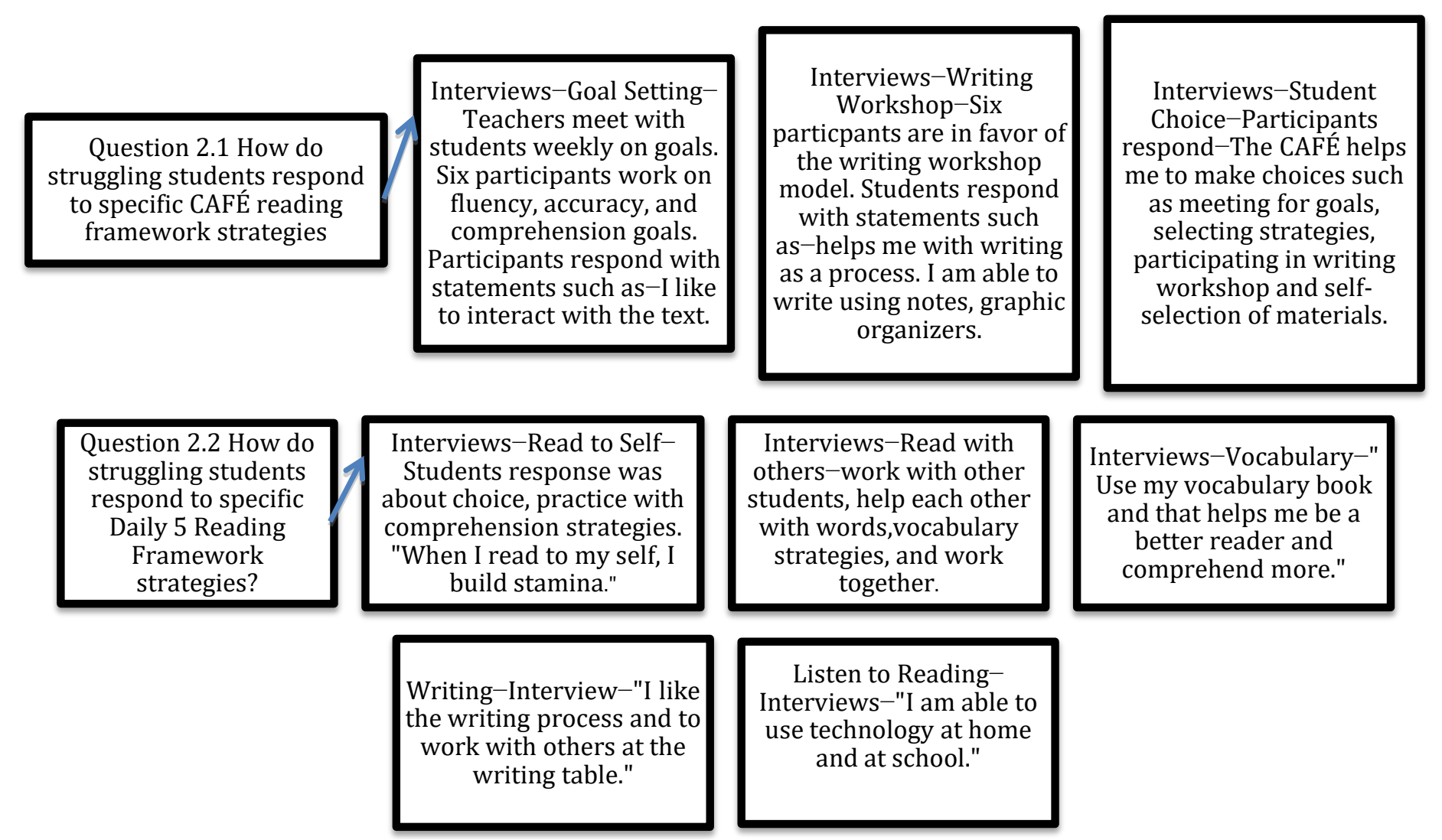

Figure 2. Question \#2-Interviews for goal setting, writing workshop. 
and whole class instruction. What is taught comes from students' needs and curriculum (Boushey \& Moser, 2009). Each student was interviewed in response to sub-question two: how do struggling students respond to specific CAFÉ reading framework strategies? Six student participants were interviewed over the 10 -week study for individual weekly sessions about specific CAFÉ strategies. The strategies were goal setting, writing workshop, and student choice. Table 1 represents the majority of responses to interview questions about CAFÉ strategies. Students were individually interviewed and each interview took about 4-5 minutes. The questions were specific to the CAFÉ strategies, to see whether students think goal-setting, writing workshop, and student choice help them with comprehension.

Sub-question two focused on how struggling students respond to specific Daily 5 reading framework strategies. Figure 2 represents the majority of responses to interview questions about Daily 5 reading framework strategies. The Daily 5 supports students in developing daily habits of reading, writing, and working with others. Daily 5 does not hold content; content comes from what is being taught, the skills and strategies students need to be good readers. As the name suggests, there are five literacy tasks for students to complete, while the teacher is able to conference with individuals and small groups. Students are trained to participate through explicit teacher modeling. The participation in the five tasks enables effective reading practice time. Therefore, students practice reading in authentic selections. The selections are read to self, read to someone, listen to reading, work on writing, and vocabulary work (Boushey \& Moser, 2006). Six students were interviewed weekly during class rotations of the Daily 5. The interviews were conducted 
for 10 weeks. Students responded to specific Daily 5 strategies with enthusiasm and many positive comments. The students enjoy work in the Daily 5 and responded in relation to work with other students, time to practice reading and writing, choice, movement from one task to another, and importance of writing workshop.

Question two also included reflection journals about goal setting. Some of the written responses about goal setting were about choice, working in a partnership with other students and the teacher, focus, and practice. Some of the written responses about participation in the writing workshop included the ability to practice, the value of organization, reading and writing connections, and the time to go through the writing process. Many of the students were in favor of a long table that included organizational materials for writing.

\section{Research Question 3}

What are struggling students' attitudes toward reading and themselves as readers?

3.1 How do you feel about reading? Do you like reading?

3.2 How do you see yourself as a reader at the beginning of the year and what is reading like now?

3.3 How do you describe yourself as a reader?

The first data source was a Garfield reading attitude survey (McKenna \& Kerr, 1990) that was given to all six participants in the study. The Garfield reading attitude survey was administered to each student at the beginning of the study and at the end of the 10 weeks. This survey is a non-referenced measure that includes Garfield cat illustrations related to reading attitudes. Four pictures depicting the cartoon character Garfield, with expressions ranging from "very happy" to "very upset," follow each item. 
Students circle the Garfield that best expressed their feelings about each written item. The survey is in a pictorial format because of its natural appeal for children and its comprehensibility by the very young.

Each item in the survey is then assigned points with " 4 " indicating the happiest Garfield. There is a scoring sheet that is used to organize this process and record results. Students were able to read the survey on their own and completed it in approximately 5 minutes. The survey is a tool that can be used with relative confidence to estimate the attitude levels of students and initiate informal assessment efforts into the role attitude shows in the development of students as readers (McKenna \& Kerr, 1990). The results of the survey were higher for recreational reading in comparison to academic reading. The participants feel happy about reading and like reading. I did notice that students scored least favorable for reading workbook pages and worksheets.

Question number three also addressed participants' attitudes toward reading and themselves as readers. Sub-question number one informed this study about how students felt about reading and if they like reading. Sub-question number two wanted to know how students see themselves as readers at the beginning of the year and what is reading like now? Sub-question number three asked how do students describe themselves as readers. One of the six students I interviewed about how she felt about reading replied that she "now likes reading since she participated in the Daily 5" and she is "able to read for long periods of time." Figure 3 depicts the contents of question number three.

The process of each student interview consisted of a set of questions in (Appendix C). Students were able to read the questions before the interview. I sat next to each 
student on the same side of the table. I reminded the student that I would write down the answers to student questions. I also told the student that there were no right or wrong answers. I advised the students to respond to the best of their ability and the interview process took ten minutes. Since this research project was conducted in my classroom, students were able to answer questions with ease.

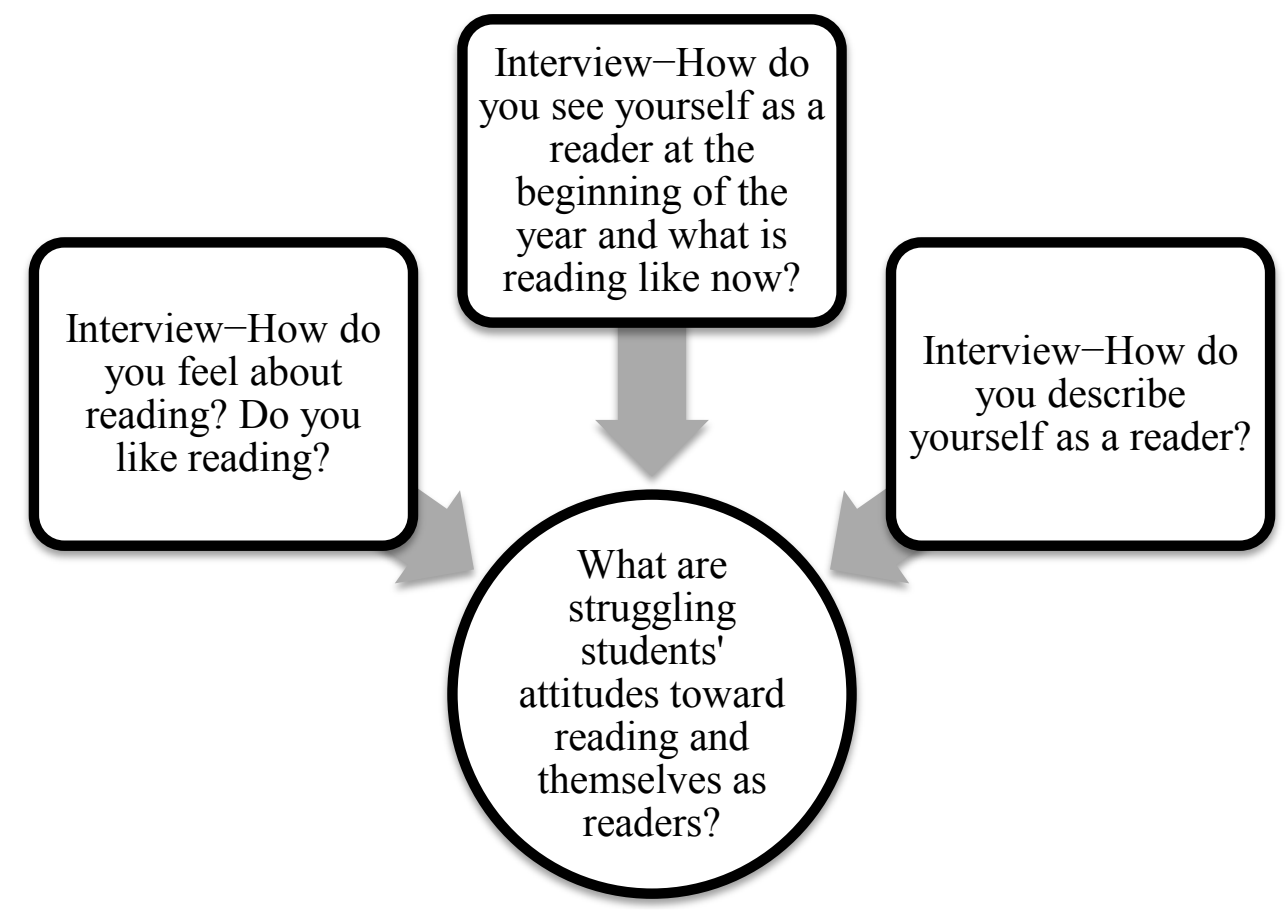

Figure 3. Question \#3-Interview questions.

I interviewed students one-on-one for 5 minutes twice a week for 10 weeks about attitudes toward reading. Each student was descriptive about their feelings for reading. Five out of six students interviewed shared many feelings about reading. Some of the words used to describe themelves as readers were excitement, knowledge, choice, stamina, practice, movement, strategies, and projects. All students reported that they liked 
reading. Students also commented on the growth they made over the year in reading. All students agreed that reading helps them become better readers. Some of the other comments were about choice of reading materials and how they participate with other students in the Daily 5. Students like to use reading to complete projects and connect reading to success in everything they accomplish. All students reported that the reason that they like reading is because of Daily 5, CAFÉ, and they are able to read all day long.

The Burke (Goodman et al., 1987) reading questionnaire assesses students' general purposes for reading. Students responded to question eight in writing: what would you like to do better as a reader and describe yourself as a reader? Students responded with answers such as read more, know the reading strategies, read at home, and work on more projects that require reading. Students used a scale of five to one, with five being a terrific reader and the overall rating that students gave themselves was five. Students thought they were terrific readers. The results of this interview question were not surprising. The students in this study always want to improve their reading skills and strategies. One student suggested that all students in the classroom work together as a team with reading.

Question three used the Draw-a-Reader illustration as another source of data to provide evidence that students are able to create another form of documentation. Draw-aReader helped the students in this study tell stories about their pictures. The documentation provided insights into student thinking about attitudes in reading. I met with students one-on-one for 4-5 minutes during the drawing process to talk about their picture. Students were able to reflect and describe themselves as readers. Students 
communicated many responses in the illustrations such as "choice of books, time to read books, excitement to read books about a variety of subjects, and use of books to complete a project."

The final data source for question three is the reflective journal writing about students' attitudes toward reading and themselves as readers. Students received the survey questions: how do you feel about reading, do you like reading, how do you see yourself as a reader at the beginning of the year and what is reading like now, and how do you describe yourself as a reader? Students wrote in their journals for at least 10 minutes each day about questions in this case study. Many of the written responses to question three were about improvement in reading due to participation in the Daily 5. All students wrote answers, such as "CAFÉ strategies help me become a better reader." "I use the CAFÉ strategies every day." Students wrote about how they feel about reading. It was no surprise to hear how much they like and enjoy reading every day. Other written comments were about reading together, reading goals, and individual conferences. Students like to "participate" in a reading classroom where they can read all day long.

\section{Research Question 4}

What kind of growth in reading comprehension did the struggling students have over one year? The study was limited to 10 weeks, but the Developmental Reading Assessment is a standardized reading test used to determine a student's instructional level in reading, accuracy, and comprehension. The Developmental Reading Assessment is administered individually to students by teachers. Students read a selection and then retell what they have read. The Developmental Reading Assessment was given in the Fall and 
in the Spring. In my research study, I used the Fall score and compared the score to the Spring score. The spring score was given during the study.

Question number 4 is a specific standardized reading test used to identify students' reading level, defined as a text in which students meet specific criteria in terms of accuracy, fluency, and comprehension. The three components are combined together and the results are one score. Students went from level M and P to Level Q and R. The beginning level $\mathrm{M}$ and $\mathrm{P}$ is equal to end of second grade. Level $\mathrm{Q}$ and $\mathrm{R}$ equate to middle and end of third grade. Students made a year's growth in fluency, accuracy, and comprehension.Table 2 displays the growth students made in reading comprehension over one year. Comprehension scores in the fall went from level 1 to level 3 at the end of the year. Students at level 1 recall one idea from the story. Students at level 3 are able to recall three ideas from the story. Fluency and accuracy were at $80 \%$ in the fall and $95-100 \%$ in the spring.

Table 2

Question \#4-Reading Achievement Test Scores

\begin{tabular}{|l|l|l|}
\hline Reading Level Change & Fluency & Comprehension \\
\hline Sergio M to Q & Fluency-Accuracy 99 & Comprehension-3 \\
\hline Kristina M to Q & Fluency-Accuracy 100 & Comprehension-3 \\
\hline Natalia M to Q & Fluency-Accuracy 100 & Comprehension-3 \\
\hline Lance P to Q & Fluency-Accuracy 100 & Comprehension-3 \\
\hline Owen M to Q & Fluency-Accuracy 100 & Comprehension-3 \\
\hline Mollie M to R & Fluency-Accuracy 95 & Comprehension-3 \\
\hline
\end{tabular}




\section{Summary}

This chapter described analysis of data and results of the study as the study related to the research questions. Throughout the data collection process, students related a meaningful connection to reading when participating in the Daily 5 and CAFÉ framework. Students communicated how each component of the literacy framework improved their reading comprehension strategies and skills. The themes that emerged from the analysis were: "We like choice," "It is helpful to set goals," "I like to participate in movement from one choice to another," and "It is fun to work with others." Each theme is expressed though the participant's voices and their responses on interviews, questionnaires, illustrations, achievement tests, surveys, and journals. The themes were also apparent during interviews, surveys, and journals.

In chapter 5, the findings are discussed according to constructivist and transactional theory along with previous literature from the field. Implications are discussed and presented to show how the data could inform policy and practice of educational professionals who work with students that have difficulty in reading comprehension. Finally, recommendations for future research are presented. 


\section{CHAPTER 5}

\section{DISCUSSION/CONCLUSION}

The purpose of this chapter is to discuss the findings related to how a reading framework impacted struggling students' reading comprehension. Through analysis of interviews, surveys, questionnaires, drawings, written responses, and achievement tests from the students who participated in the reading framework, three key themes were identified: (a) Choice: students valued having choices in the selection of reading and writing materials during Daily 5 rotations; (b) Goals: students noted that setting their reading goals in CAFÉ assisted their comprehension and enjoyment of reading; and (c) Collaboration: students enjoyed and learned from collaborating with peers during Daily 5 and CAFÉ instruction. This chapter first discusses the research findings. Implications for teaching and recommendations for future research studies beyond this grade level are also addressed. Final thoughts summarize the overall issues of how a reading framework can impact struggling readers so that they can improve their reading comprehension.

\section{Synthesis of Findings}

The overall question of the study is whether students actually became better readers and writers by the end of the year through their participation in the reading framework. To address this larger issue, let us look once again at their scores on the developmental reading assessment from the first of the year to the year end of the study. Students were given the Developmental Reading Assessment at the beginning of the school year that measures accuracy, fluency, and reading comprehension. The 
developmental reading assessment is a standardized reading test used to determine a student's instructional level in reading. The six students in this study were given reading assessments in the fall and again in the spring. In my years of experience, I realize that students that struggle with reading comprehension do not always make a year's growth. In the study, based on the reading assessment, students in the study made at least one year's growth in reading comprehension (see Table 2) and were able to demonstrate their understanding in writing. When I interviewed students about growth in reading comprehension, they claimed that making choices, creating reading and writing goals by themselves and with the teacher as well as working with peers helped them with growth in reading comprehension.

The core elements of Daily 5 and CAFÉ are fostering trust and respect, building community, offering students choices in reading selections, increasing student accountability, using activities based on brain research during breaks, focusing on smooth transitions, and encouraging independence (Boushey \& Moser, 2014). Yet, even with this powerful list of elements in the reading framework, Boushey and Moser do not directly address their work to assist struggling students who are the focus of this study. The struggling fourth grade students in my study reported that they valued many of the core elements in the framework as listed above; however, students repeated and analysis of the data indicated that having choices, setting goals and collaborating with peers seemed to be the most helpful to them. I write about these three key themes below. 


\section{1-Making Choices}

Student choice was one of the main themes that emerged in this study. One consistent theme from student responses in Draw-a-Reader, interviews, and reflection journals was that students valued the ability to choose a book and a place in which to do their work. Manning and Manning (1984) suggested how important choice is to increase reading comprehension. R. C. Anderson, Shirey, Wilson, and Fielding (1987) agreed that choice is related to interest and motivation, which are directly related to learning. Although there seems to be no research that says choice directly ensures reading comprehension growth, choice does seem to be related to motivation and student interest, which are both related to learning (R. C. Anderson et al., 1987). Worthy (1996) emphasized that allowing students to make choices about reading and writing materials expanded the likelihood that students would respond more favorably to instruction. Even

a small choice in a reading task increased learning from the task and enhanced interest in the activity (Cordova \& Lepper; 1996; Iyengar \& Lepper, 1999). Furthermore, Guthrie and Wigfield (2000) suggested that providing student choice enhances student commitment to reading.

Transactional theory helps to explain the connection students make during the selection of what and where they read. Rosenblatt (1938/1995) argued that reading is more than knowing the words on the page. It involves a transaction between the student and the text. This theory looks at the background of the reader, what the reader brings to the text, their expectations of reading, and choices students make as they read (Rosenblatt, 1985). Therefore, what the student brings to the text like a positive attitude 
can enhance the transaction. Thus, if, as part of this transaction, the students are allowed to make choices, then, it seems that the transaction can be more fruitful. In the study, students themselves indicated that they valued having choices in what they read. Using the CAFÉ and Daily 5 reading framework allowed students to be more engaged in the transaction.

The transaction between a reader and the text is crucial to comprehension. Beyond the reader and the text, what is the classroom environment and what the teacher does as part of this transaction are important (Rosenblatt, 1985). Therefore, when the teacher teaches comprehension strategies, scaffolds comprehension strategies, and makes reading and writing connections visible to students, she is enhancing the reading transaction for students.

\section{2-Setting Goals}

The next theme that emerged for how students preceive their experience in Daily 5 and CAFÉ reading framework is setting reading goals. Reading goals are established during CAFÉ strategy instruction such as comprehension, accuracy, fluency, and vocabulary expansion. During student interviews, Draw-a-Reader activity, and reflection journals, students continued to repeat how goal setting helps them improve in reading comprehension. Once the student, with the guidance of the teacher, chooses two to three of the comprehension strategies, the student incorporates the strategies into their goals to improve reading comprehension. The whole process takes about 4-5 minutes. Setting goals leads students along a clear path for success, and students develop ownership over their learning (Boushey \& Moser, 2014). Chappuis, Chappuis and Stiggins (2009) 
claimed that teachers need to ensure that goals connect with students and the work they are focused on learning.

In the study, the students stated that goal setting helped them become better readers and writers because they were able to learn a new strategy from the teacher, practice the strategy, and use it to read and write better. Johnson, Allington, and Afflerbach (1985) found that students must have clear and specific goals to apply a newly learned skill. Teachers model the goal-setting strategies and provide students with many opportunities to practice and use the strategies to accomplish their reading goals (Duffy, 2002; Pressley \& McCormick, 1995). In CAFÉ students set goals that included practice in making predictions, inferring, questioning, summarizing, visualizing, and organizing (Keene \& Zimmermann, 1997; W. H. Miller, 2002; Pardo, 2002).

\section{3-Collaborating With Others}

Collaboration with others is another theme that emerged from the interviews, questionnaire, and reflection journals. Students wrote many stories about how the Daily 5 framework helped them communicate about reading and writing about their own work as well as help others with theirs. Boushey and Moser (2014) argued that a sense of community empowers students to hold the classroom accountable for learning, respect, and kindness. Within the reading community, once the culture of honor and respect has been established, the community becomes a place where goals are achieved and progress is made in reading comprehension (Boushey \& Moser, 2014). In the Daily 5 framework, the community and culture are built from a foundation of trust and respect to create an environment of learning. Students are taught from the first days of school to help and care 
for each other. The community in the classroom is a shared place where teacher and students write and read together (Boushey \& Moser, 2014). As students described what happens to them in the Daily 5, they consistently wrote and talked about how reading and writing in their classroom was a collaborative effort. The collaborative team worked together to build new information from the text with past knowledge of reading. Rosenblatt (1978) argued that every reading experience is unique to each individual. Rosenblatt's transactional theory not only suggests that knowledge of literature is created by the individual but is also developed through exchanges with texts and other readers. The epistemology of the transactional theory returns the responsibility for learning to the student; yet, when collaborating with others, others facilitate the transaction.

\section{Three Key Findings: Interaction}

As I have done above, I have examined each of the key themes individually. Yet, all three were present in the same reading framework. Christie (2005) found that comprehension is fostered when students participate in a reading activity and make reading choices that represent their personal interests and overall goals. Pressley and Hilden (2002) suggested that student attitudes and motivation will increase when teachers provide interesting texts, choices in reading and writing, and help students set authentic purposes for reading. Christie (2005) and Pressley and Hilden (2002) showed us how the three findings of the study can interact positively: making choices, setting goals and collaborating with peers will lead to an increase in student attitudes, motivation and achievement. 
The theory of constructivism helps to explain the results of the study. One of the tenets of constructivism in the classroom is that the teacher needs to adapt teaching to address students' individual needs. In the constructivist classroom, student work is done in groups or pairs, process is as important as product, learning is interaction-building on what students already know, and students develop their own goals. In the reading framework, instruction is student-centered and allows for choice and individuality in practical tasks. Brooks and Brooks (1993) emphasized constructivism as a process in which students create new understandings with coaching, moderating, and suggesting. As discussed in chapter 2 , constructivism portrays the reader as actively building a mental image by combining new information from the text with past knowledge (J. R. Anderson, 1983; Johnson-Laird, 1983; Kintsch, 1974). Since the constructivist theory claims that knowledge is active and constructed by the learner, learning depends to a significant extent on the learner's internal drive to understand and promote the learning process (Vygotsky, 1930/1978). Through making choices, setting goals and collaborating with others, the students were very active constructors of their reading experiences. They had many opportunities to be engaged in reading and work with others. From a constructivist perspective, their engagement led to significant learning of new reading strategies and more success.

The goal of this case study was to address the very important question about how to improve reading comprehension for struggling fourth grade students. Reading comprehension is a key factor in academic success, For students who are not successful by the fourth grade (9 years old), lack of success in reading has long term consequences. 
Studies in the United States have indicated that many students struggle with reading comprehension (Allington, 2012). Studies also indicate that when students fail in reading, they rarely catch up (Allington, 2012). Struggling students in reading comprehension encounter negative consequences such as long-term remediation, special education classes, or grade retention. As students continue through school, the gap becomes more pronounced and students are not always able to reach grade level reading and writing goals (The Learning First Alliance, 1998; National Reading Panel, 1999; Rashotte, Torgesen, \& Wagner, 1997; Torgesen, 1998).

Reading comprehension is a critical component of functional literacy. Beyond this, reading comprehension is essential to life. In order to survive and thrive in today's world, individuals must be able to comprehend basic texts such as bills, transportation schedules, housing agreements and prescription advice. If you are not able to read and comprehend what you read, you are not able to live safely, socially, and intellectually. Comprehension is a crucial aspect of reading. I was determined to find ways to help my students, especially my struggling students become more engaged in reading and comprehend what they read. Therefore, I explored a promising reading framework, the Daily 5 and CAFÉ, on fourth grade struggling students' reading attitudes, engagement, and comprehension. This qualitative case study defined, described, and analyzed in what ways the Daily 5 and CAFÉ (an acronym for comprehension, accuracy, fluency, and expand vocabulary) literacy framework (Boushey \& Moser, 2014) impacted fourth grade students who struggle with reading comprehension. 


\section{Implications for Classroom Practice}

Reading instruction based on informational texts that includes skill development for content knowledge and vocabulary, offers potential to the nation's stagnant reading comprehension scores as reported by National Assessment of Educational Progress (National Center for Education Statistics, 2014) and international comparisons of reading tests (National Center for Education Statistics, 2011). To meet the needs of all students in Oregon, a four-tiered Response to Intervention model is used to differentiate levels of instructional support. Within the four tiers of instruction based on student data, guidance on setting reading goals, assessing, and differentiating instruction, the Daily 5 and CAFÉ help to provide the necessary framework to support all students. The benefits of Daily 5 for teachers and schools are to develop authentic reading and writing choices, work independently toward personalized goals and produce highly engaged students that love literacy (Boushey \& Moser, 2014). Explicit comprehension instruction and time to practice should not be delayed if students struggle to read informational texts independently (Beck \& McKeown, 2001; Snow et al., 1998). Boushey and Moser (2014) argued that teachers need to set the bar high for expected reading behaviors so that all students will make growth in reading comprehension. Elementary teacher education programs must prepare their undergraduate students for the important role that they will play in many aspects of teaching reading and writing.

The implications of this study for classroom practice are that the framework structures literacy so students develop lifelong habits of reading, writing, and working independently. Throughout Daily 5 and CAFÉ practice, teachers are expected to 
implement management of rigorous activities, attend to classroom behavior, and make students accountable. At the same time, the environment in the classroom consists of soft lighting, comfortable chairs, rugs, and even pillows. By using these materials, teachers create spaces where students can be more successful, comfortable, and focused. Daily 5 is a student-centered way to provide instruction during literacy blocks of time. The framework emphasizes teacher modeling and practice for reading routines.

This study can be viewed from a broader perspective, beyond the individual classroom where data were collected. When Oregon adopted the Common Core in 2010, Oregon joined other states in the pursuit of a common, standards-based education for Oregon students in kindergarten through high school. During Daily 5 practice, it is possible to teach lessons that are goal specified by the Common Core. Common standards can incease the likelihood that all students, no matter where they live, are ready for the workplace and college. Unfortunately, many of our students are not prepared for independent reading and high-level comprehension of complex tests after grade 12 . As little as $7-15 \%$ of elementary instruction occurs with expository text (Hoffman, Sabo, Bliss, \& Hoy, 1994; Yopp \& Yopp, 2000). The use of informational texts used in the Daily 5 and CAFÉ build crtitical background knowledge and vocabulary, develop higherlevel thinking and foster analytical levels of comprehension. Informational texts also provide opportunities to develop the reading-writing connection as students write about what they read (Duke et al., 2003). The reading framework used in this program focuses on the reading and understanding of a variety of student-chosen texts that include informational texts. 


\section{Recommendations for Future Research}

Suggestions for further research to increase struggling student comprehension would be to investigate increasing vocabulary practice during Daily 5 and CAFÉ instruction. Students would be tested on with the Criterion Vocabulary Test (Carreker, 2004). The vocabulary test consists of 40 multiple choice items on a pre-test and posttest. Students look at the target word and pick a synonym from four options. The Criterion Vocabulary Test results would help to identify vocabulary words that students struggle with in order to comprehend during reading.

Another study to increase vocabulary would be results from the Peabody Picture Vocabulary Test. The test is intended to provide a quick estimate of verbal ability of vocabulary (Dunn \& Dunn, 1997). The Peabody Picture Vocabulary Test is also administered to students with reading problems. Once the test is administered, the test

measures response to vocabulary instruction. Vocabulary instruction is included in CAFÉ which comprehension, accuracy, fluency, and vocabulary.

Another study would be to investigate if a larger population of students would produce different results in comparison to six students.

\section{Summary}

This study demonstrated the power of the Daily 5 and CAFÉ for struggling students in the fourth grade. For teachers, the study offers hope that the implementation of the framework can keep all students engaged in productive literacy work for every hour of every classroom day (Boushey \& Moser, 2009). When involved in the framework, students are able to select from five reading and writing choices in read to 
self, work on writing, read to someone, listen to reading, and word work. During Daily 5 rotations, teachers meet with individual students through whole-group and small-goup instruction and during one-on-one conferences. During CAFÉ (comprehension, accuracy, fluency, expand vocabulary), students choose individualized goals and learn strategies for comprehension. The student and teacher meet to discuss CAFÉ goals and monitor progress. Instruction is tailored in reading and writing to meet the needs of every student. Therefore, literacy time is structured to develop not only current reading achievement but, also, a set of lifelong habits of reading, writing, and working independently. The beauty of this framework is that it does not require expensive materials, complicated training, or a radical change to current literacy approaches. The framework provides a structure to collaborate with students and a system to set goals and foster student independence in literacy. And, the good news is that fourth grade students who struggle to comprehend what they read are quite successful in the program. 


\section{REFERENCES}

Allington, R. L. (1983). Fluency: The neglected goal. The Reading Teacher, 36, 556-561.

Allington, R. L. (2009). If they don't read much . . 30 years later. In E. H. Hiebert (Ed.), Reading more, reading better (pp. 30-54). New York, NY: Guilford.

Allington, R. L. (2012). What really matters for struggling readers: Designing researchbased programs ( $3^{\text {rd }}$ ed.). Boston, MA: Allyn and Bacon.

Almasi, J. F., \& Gambrell L. B. (1994). Sociocognitive conflict in peer-led and teacherled discussions of literature (Research Report No. 12). Athens, GA: National Reading Research Center.

Anderson, J. R. (1983). The architecture of cognition. Cambridge, MA: Harvard University.

Anderson, R. C., Shirey, L. L., Wilson, P. T., \& Fielding, L. G. (1987). Interestingness of children's reading material. In R. E. Snow \& M. J. Farr (Eds.), Aptitude, learning, and instruction: Vol. 3. Cognitive and affective process analyses (pp. 287-299). Hillsdale, NJ: Erlbaum.

Anderson, R. C., Wilson, P. T., \& Fielding, L. G. (1988, Summer). Growth in reading and how children spend their time outside of school. Reading Research Quarterly, 23(3), 285-303.

Armbruster, B. B., Lehr, F., \& Osborn, J. (2001). Put reading first: The research building blocks for teaching children to read. Ann Arbor, MI: Center for the Improvement of Early Reading Achievement.

Bandura, A. (1977). Social learning theory. Englewood Cliffs, NJ: Prentice Hall.

Barr, R., \& Dreeben, R. (1991). Grouping students for reading instruction. In R. Barr, M. L. Kamil, P. B. Mosenthal, \& P. D. Pearson (Eds.), Handbook of reading research (Vol. 2; pp. 885-910). Mahwah, NJ: Lawrence Erlbaum Associates.

Beck, I. L., \& McKeown, M. G. (2001). Text talk: Capturing the benefits of read-aloud experiences for young children. The Reading Teacher, 55(1), 10-20.

Benson, P. (2001). Autonomy in language teaching and learning. Language Teaching, 40, 21-40. 
Bogdan, R. C., \& Biklen, S. K. (2003). Qualitative research for education: An introduction to theories and methods ( $4^{\text {th }}$ ed.). New York, NY: Pearson Education.

Boushey, G., \& Moser, J. (2006). The Daily 5: Fostering literacy independence in the elementary grades. Portland, ME: Stenhouse.

Boushey, G., \& Moser, J. (2009). The CAFÉ book: Engaging all students in daily literacy assessment and instruction. Portland, ME: Stenhouse.

Boushey, G., \& Moser, J. (2012). Big ideas behind Daily 5 and CAFÉ. The Reading Teacher, 66(3), 172-178. doi:10.1002/TRTR.01116

Boushey, G., \& Moser, J. (2014). The Daily 5: Fostering literacy independence in the elementary grades $\left(2^{\text {nd }}\right.$ ed.). Portland, ME: Stenhouse.

Bransford, J. D., Barclay, J. R., \& Franks, J. J. (1972). Sentence memory: A constructive versus interpretative approach. Cognitive Psychology, 172(3), 193-209.

Brantlinger, E., Jimenez, R., Klingner, J., Pugach, M., \& Richardson, V. (2005). Qualitative studies in special education. Exceptional Children, 71(2), 195-207.

Brooks, M., \& Brooks, J. (1993). In search of understanding: The case for constructivist classrooms. Alexandria, VA: Association for Supervision and Curriculum Development.

Brooks, M., Hamann, L., \& Vetter, M. (1997). Improving reading comprehension and vocabulary development in at-risk students (Master's thesis, Saint Xavier University). Retrieved from http://files.eric.ed.gov/fulltext/ED410535.pdf

Brophy, J. (1998). Motivation students to learn. New York, NY: McGraw-Hill.

Brown A. L., Palincsar A. S., \& Armbruster, B. (1984). Instructing comprehension fostering activities in interactive learning situation. In H. Mandel, N. Stein, \& T. Trabasso (Eds.), Learning from texts (pp. 255-286). Hillsdale, NJ: Lawrence Erlbaum.

Brown, J. S., Collins, A., \& Duguid, P. (1989). Situated cognition and the culture of learning. Educational Researcher, 18(1), 32-34.

Brownell, M. T. (2000, November). An interview with: Dr. Michael Pressley. Intervention in School and Clinic, 36, 105-108.

Bruner, J. (1986). Actual minds, possible worlds. Cambridge, MA: Harvard University Press. 
Carreker, S. (2004). Developing metacognitive skills: Vocabulary and comprehension. Bellaire, TX: Neuhaus Education Center.

Catts, H., Hogan T., \& Adolf, S. (2005). Developmental changes in reading and reading disabilities. In H. Catts \& A. Kamhi (Eds.), Connections language and reading disabilities (pp. 25-40). Mahwah, NJ: Erlbaum.

Cazden, C. B., John, V., \& Hymes, D. (Eds.). (1972). Functions of language in the classroom. New York, NY: Teachers College Press.

Chall, J. S. (1983). Stages of reading development. New York, NY: Harcourt Brace.

Chappuis, S., Chappuis, J., \& Stiggins, R. (2009). Supporting teaching learning teams. Educational Leadership, 66(5), 56-60.

Christie, F. (2005). Language education in the primary years. Sydney, Australia: University of New South Wales Press.

Cilia-Duncan, J. (2008). Collaborative action research: The Daily 5. Retrieved from www.lessonpaths.com/learn/mmHosted/286133

Cordova, D., \& Lepper, M. (1996). Intrinsic motivation and the process of learning. Beneficial effects of contextualization, personalization, and choice. Journal of Educational Psychology, 88, 715-730.

Creswell, J. W. (1998). Qualitative inquiry and research design: Choosing among five traditions. Thousand Oaks, CA: Sage.

Creswell, J. W. (2002). Educational research: Planning, conducting, and evaluating quantitative and qualitative approaches to research. Upper Saddle River, NJ: Merrill/Pearson Education.

Creswell, J. W. (2003). Research design: Qualitative, quantitative, and mixed methods approaches (2nd ed.). Thousand Oaks, CA: Sage.

Cushman, E., \& Emmons, C. (2002). Contact zones made real. In G. Hull \& K. Schultz (Eds.), School's out: Bridging out-of-school literacies with classroom practice (pp. 203-232). New York, NY: Teachers College Press.

Denzin, N. K., \& Lincoln, Y. S. (1994). Introduction: Entering the field of qualitative research. In N. K. Denzin \& Y. S. Lincoln (Eds.). Handbook of qualitative research (pp. 1-17). Thousand Oaks, CA: Sage.

Dewey, J. (1933). How we think. Boston, MA: D. C. Heath \& Co. 
Duffy, G. (2002). The case for direct explanation of strategies. In C. Block \& M. Pressley (Eds.), Comprehension instruction: Research-based best practices (pp. 28-41). New York, NY: Guilford.

Duke, N. K. (2003, March 7). Comprehension instruction for intentional text. Presentation at the annual meeting of the Michigan Reading Association, Grand Rapids, MI.

Duke, N. K., Bennett-Armistead, V. S., \& Roberts, E. M. (2003). Bridging the gap between leaning to read and reading to learn. In D. M. Barone \& L. M. Morrow (Eds.), Literacy and young children: Research-based practices (pp. 226-242). New York, NY: Guilford.

Duke, N. K., \& Carlisle, J. F. (2011). The development of comprehension. In M. L. Kamil, P. D. Pearson, E. B. Moje, \& P. Afflerbach (Eds.), Handbook of reading research (Vol. 4; pp. 199-228). London, UK: Routledge.

Duke, N. K., \& Pearson, P. D. (2002). Effective practices for developing reading comprehension. In A. E. Farstrup \& S. J. Samuels (Eds.), What research has to say about reading instruction ( $3^{\text {rd }}$ ed., pp. 205-242). Newark, DE: International Reading Association.

Dunn, L. M., \& Dunn, L. M. (1997). Peabody picture vocabulary test ( $3^{\text {rd }}$ ed.). Circle Pines, MN: American Guidance Service.

Durkin, D. (1978). What classroom observations reveal about reading comprehension instruction. Reading Research Quarterly, 14(4), 481-533.

Ellis, E. S., Worthington, L., \& Larkin, M. J. (1994). Executive summary of research synthesis on effective teaching principles and the design of quality tools for educators (Technical Report No. 6). Eugene, OR: University of Oregon, National Center to Improve the Tools of Educators. Retrieved from http://idea.uoregon. edu/-nncite/documents/tecrep/other.html

Ericsson, K. A. (2003). Exceptional memorizers: Made, not born. Trends in Cognitive Sciences, 7(6), 233-235.

Fisher, D., \& Frey, N. (2007). Implementing a school-wide literacy framework: Improving achievement in an urban elementary school. The Reading Teacher, 61, $32-45$.

Fisher, D., \& Frey, N. (2009). Building background knowledge. Portsmouth, NH: Heinemann.

Gambrell, L. B. (2011). Seven rules of engagement. The Reading Teacher, 65(3), 172-178. 
Geertz, C. (1973). The interpretation of culture. New York, NY: Basic Books.

Gersten, R., \& Baker, S. (2000). What we know about effective instructional practices for English language learners. Exceptional Children, 66, 454-470.

Goodman, Y. M., Watson, D. J., \& Burke, C. L. (1987). Reading Miscue Inventory: Alternative procedures. Katonah, NY: Richard C. Owen.

Graves, M. F., \& Fitzgerald, J. (2003). Scaffolding reading experiences for multilingual classrooms. In G. G. Garcia (Ed.), English learners reaching the highest level of English literacy (pp. 96-124). Newark, DE: International Reading Association.

Grinder, M. (1995). ENVoY: Your personal guide to classroom management. Battle Ground, WA: Michael Grinder and Associates.

Guthrie, J. T., \& Wigfield, A. (2000). Engagement and motivation in reading. In M. L. Kamil, P. B. Mosenthal, P. D. Pearson, \& R. Barr (Eds.), Handbook of reading research (Vol. 3, pp. 403-422). Mahwah, NJ: Erlbaum.

Hart, B., \& Risley, T. R. (2003, Spring). The early catastrophe: The 30 million word gap by age 3. American Educator, pp. 4-9. Retrieved from www.aft.org/pubsreports/ american_educator/spring2003/catastrophe.html

Hatch, E. (1978). Discourse analysis and second language acquisition. In E. M. Hatch (Ed.), Second language acquisition: A book of readings (pp. 401-435). Rowley, MA: Newbury House.

Herrmann, A. W. (1989). Teaching writing with peer response groups. Bloomington, IN: ERIC Clearinghouse on Reading and Communication Skills. (ERIC Document Reproduction Service No. ED307616)

Hoffman, J., Sabo, D., Bliss, J., \& Hoy, W. (1994). Building a culture of trust. Journal of School Leadership, 4, 484-501.

Horowitz, F. D., Darling-Hammond, L., \& Bransford, J. with Comer, J., Rosebrock, K., Austin, K., \& Rust, F. (2005). Education teachers for developmentally appropriate practice. In L. Darling-Hammond \& J. Bransford (Eds.), Preparing teachers for a changing world: What teachers should learn and be able to do (pp. 88-125). San Francisco, CA: Jossey-Bass.

Hoyt, L. (2009). Revisit, reflect, retell. Portsmouth, NH: Heinemann.

Iyengar, S., \& Lepper, M. (1999). Rethinking the value of choice: A cultural perspective on intrinsic motivation. Journal of Personality and Social Psychology, 76, 349-366. 
Jacob, E. (1997). Context and cognition: Implications for educational innovators and anthropologists. Anthropology and Education Quarterly, 28(1), 1-19.

Jimenez, L., \& Duke, N. K. (2011). Interest matters: Fourth-graders reading multiple high and low-interest texts. Unpublished manuscript, Michigan State University.

Johns, J. L., \& Lenski, S. L. (2005). Improving reading: Strategies and resources. Dubuque, IA: Kendal/Hunt.

Johnson, P., Allington, R., \& Afflerbach. (1985, March). The congruence of classroom and remedial reading instruction. The Elementary School Journal, 85(4), 465-477. Retrieved from http://www.jstor.org./stable/1001149

Johnson-Laird, P. N. (1983). Mental models. Cambridge, MA: Harvard University Press.

Katz, L. G., \& Chard, S. C. (1989). Engaging children's minds: The project approach. Norwood, NJ: Ablex. (ERIC Document Reproduction Service No. ED407074)

Keene, E.O., \& Zimmermann, S. (1997). Mosaic of thought: Teaching comprehension in a reader's workshop. Portsmouth, NH: Heinemann.

Kelly, G. (1955). The psychology of personal constructs. New York, NY: W. W. Norton.

Kintsch, W. (1974). The representation of meaning in memory. Hillsdale, NJ: Erlbaum.

Kucer, S. B. (2001). Dimensions of literacy: A conceptual base for teaching reading and writing in school settings. Mahwah, NJ: Lawrence Erlbaum.

LaBerge, D., \& Samuels, S. J. (1974). Toward a theory of automatic information processing in reading. Cognitive Psychology, 6(2), 293-323. doi:10.1016/00100285(74)90015-2

Labinowicz, E. (1980). The Piaget primer. Menlo Park, CA: Addison-Wesley.

LaShomb, J. M. (2011). The effects of the Daily 5, developed by Gail Boushey and Joan Moser, on classroom literacy instruction (Master's thesis, State University of New York College at Brockport). Retrieved from http://digitalcommons. brockport.edu/cgi/viewcontent.cgi?article $=1158 \&$ context $=$ ehd_theses

Learning First Alliance. (1998). Every child reading. American Education, 22(1\&2), 52-63.

Liang, L. A., \& Dole, J. A. (2006). Help with teaching reading comprehension: Comprehension instructional frameworks. The Reading Teacher, 59(8), 742-753. 
Logan G. D. (1997). Automaticity and reading: Perspectives from the instance theory of automatization. Reading and Writing Quarterly, 13, 123-146. doi:10.1080/1057356970130203

Lonigan, C. (2003). Development and promotion of emergent literacy skills in children at-risk of reading difficulties. In B. Foorman (Ed.), Preventing and remediating reading difficulties: Bringing science to scale (pp. 23-50). Baltimore, MD: York.

Luke, A., \& Freebody, P. (1999). A map of possible practices: Further notes on the four resources model. Sydney, NSW, Australia: Practically Primary, Primary Teachers Association of Australia.

Lyons, C. (2003). Teaching struggling readers: How to use brain-based research to maximize learning. Portsmouth, NH: Heinemann.

Madden, L. (1988, December). Improve reading attitudes of poor readers through cooperative reading teams. Reading Teacher, 42, 194-199.

Manning, G. L., \& Manning, M. (1984). What models of recreational reading make a difference? Reading World, 23, 375-380.

Maxwell, J. A. (2005). Qualitative research design: An interactive approach (2 ${ }^{\text {nd }}$ ed.). Thousand Oaks, CA: Sage.

McKenna, M. C., \& Kerr, D. J. (1990). Measuring attitude toward reading: A new tool for teachers. The Reading Teacher, 43, 626-639.

McLaughlin, M., \& Allen, M. B. (2009). Guided comprehension in grades 3-8 (2 ${ }^{\text {nd }}$ ed.). Newark, DE: International Reading Association.

Merriam, S. B. (2009). Qualitative research: A guide to design and implementation. San Francisco, CA: Jossey-Bass.

Mertens, D. M. (1998). Research methods in education and psychology: Integrating diversity with quantitative and qualitative approaches. Thousand Oaks, CA: Sage.

Miles, M. B., \& Huberman, A. M. (1994). Qualitative data analysis (2 ${ }^{\text {nd }}$ ed.). Thousand Oaks, CA: Sage.

Miller, S. D., \& Faircloth, B. S. (2009). Motivation and reading comprehension. In S. E. Israel \& G. G. Duffy (Eds.), Handbook of research on reading comprehension (pp. 307-322). New York, NY: Routledge.

Miller, W. H. (2002). Reading skills problem solver. Paramus, NJ: The Center for Applied Research. 
Moats, L. C. (1995). Spelling: Development, disabilities, and instruction. Baltimore, MD: York.

Moje, E. B., Ciechanowski K. M., Kramer K., Ellis L., Carrillo R., \& Collazo, T. (2004). Working toward third space in content area literacy: An examination of everyday funds of knowledge and discourse. Reading Research Quarterly, 39(1), 38-70.

National Center for Education Statistics. (2011). PIRLS 2011 results. Retrieved from http://nces.ed.gov/surveys/pirls/pirls2011.asp

National Center for Education Statistics. (2014). Reading assessment: Retrieved from http://www.intensive intervention.org/chart/progress-monitoring/12839

National Reading Panel. (1999). Teaching children to read: An evidence-based assessment of the scientific literature on reading and its implications for reading instruction. Washington, DC: Author. Retrieved from http://www.national reading panel.org/publications/publications.htm

Onofrey, K., \& Theurer, K. (2007). What's a teacher to do: Suggestions for comprehension strategy instruction. The Reading Teacher, 60(7), 681-684. doi:10.1598/RT.60.7.9

Palincsar, A. S., \& Brown, A. (1984). Reciprocal teaching of comprehension: Fostering and comprehension monitoring activities. Cognition and Instruction, 1(2), 117-175.

Palincsar, A. S., Ogle, D. S., Jones, B. F., \& Carr, E. G. (Eds.). (1986). Teaching reading as thinking. Oak Brook, IL: North Central Regional Laboratory.

Pardo, L. S. (2002). Book club for the twenty-first century. Illinois Reading Council Journal, 30(4), 14-23.

Pardo, L. S. (2004). What every teacher needs to know about comprehension. The Reading Teacher, 58(3), 272-281.

Parker, R., Hasbrouck, J., \& Denton, C. (2002). How to tutor students with reading comprehension problems. Preventing School Failure, 47(1), 45-47.

Patton, M. (1990). Qualitative evaluation and research methods. Beverly Hills, CA: Sage.

Pearson, P. D., \& Gallagher, M. C. (1983). The instruction of reading comprehension. Contemporary Educational Psychology, 8(3), 317-344.

Perfetti, C. A. (1985). Reading ability. New York, NY: Oxford University Press. 
Peterson, D. (2011). An examination of the Daily 5 and CAFÉ book for use in the Somerset School District's professional development program (Master's thesis, University of Wisconsin-Stout). Retrieved from http://www2.uwstout.edu/ content/lib/thesis/2011/2011petersond.pdf

Piaget, J. (1977). The essential Piaget: An interpretive reference and guide (H. E. Gruber \& J. J. Voneche, Eds.). New York, NY: Basic Books.

Piaget, J. (1985). The equilibration of cognitive structures. Chicago, IL: University of Chicago Press.

Pressley, M., \& McCormick, C. (1995). Cognition, teaching, and assessment. New York, NY: HarperCollins.

Pressley M., \& Hilden, K. (2002). How can children be taught to comprehend text better? In M. L. Kamil, J. B. Manning, \& H. J. Walberg (Eds.), Successful reading instruction: Research in educational productivity (pp. 33-51). Greenwich, CT: Information Age.

Qian, D. D. (2002). Investigating the relationship between vocabulary knowledge and academic reading performance: An assessment perspective. Language Learning, 52(3), 513-536.

Rashotte, C. A., Torgesen, J. K., \& Wagner, R. K. (1997). Growth in reading accuracy and fluency as a result of intensive intervention. Paper presented at the annual meetings of the Florida Branch of the International Dyslexia Association, Miami, FL, September.

Rasinski, T. V. (2006). A brief history of reading fluency. In S. Samuels \& A. Farstop (Eds.). What research has to say about fluency instruction (pp. 70-93). Newark, DE: International Reading Association.

Roehler, L. R., \& Cantlon, D. J. (1997). Scaffolding: A powerful tool in social constructivist classrooms. In K. Hogan \& M. Pressley (Eds.). Scaffolding student learning: Instructional approaches and issues (pp. 6-42). Cambridge, MA: Brookline Books.

Rosenblatt, L. M. (1978). The reader, the text, the poem: The transactional theory of literary work. Carbondale, IL: Southern Illinois University Press.

Rosenblatt, L. M. (1985). The transactional theory of the literacy work: Implications for research. In C. R. Cooper (Ed.), Research response to literature and the teaching of literature (pp. 33-53). Norwood, NJ: Ablex.

Rosenblatt, L. M. (1995). Literature as exploration. New York, NY: The Modern Language Association of America. (Original work published 1938) 
Rosenshine, B. V, \& Meister, C. (1995). Scaffolds for teaching higher-order cognitive strategies. In. A. C. Ornstein (Ed.), Teaching: Theory into practice (pp. 134-153). Boston, MA: Allyn \& Bacon.

Routman, R. (2003). Reading essentials: The specifics you need to teach reading well. Portsmouth, NH: Heinemann.

Rumelhart, D. E. (1977). Toward an interactive model of reading. In S. Dornic (Ed.), Attention and performance VI (pp. 576-603). Hillsdale, NJ: Erlbaum.

Rust, C., O’Donovan, B., \& Price, M. (2005). A social constructivist assessment process model: How the research literature shows us this could be best practice. Assessment and Evaluation in Higher Education, 30(3), 233-241.

Saldana, J. (2013). The coding manual for qualitative researchers. Thousand Oaks, CA: Sage.

Silver, H. R., Strong, R. W., \& Perini, M. J. (2001). Tools for promoting active, in-depth learning $\left(2^{\text {nd }}\right.$ ed.). Ho-Ho-Kus, NJ: The Thoughtful Education Press.

Smith, F. (1975). Comprehension and learning: A conceptual framework for teachers. New York, NY: Holt Rinehart and Winston.

Snow, C. E., Barnes, W. S., Chandler, J., Hemphill, L., \& Goodman, I. F. (1991). Unfulfilled expectations: Home and school influences on literacy. Cambridge, MA: Harvard University Press.

Snow, C. E., Burns, S., \& Griffin, P. (Eds.). (1998). Preventing reading disabilities in young children. Washington, DC: National Academy Press.

Stake, R. E. (1995). The art of case study research. Thousand Oaks, CA: Sage.

Stanovich, K. E. (1990). A call for an end to the paradigm wars in reading research. Journal of Reading Behavior, 22, 221-231.

Taylor, B. M., Pearson, P. D., Peterson, D. S., \& Rodriguez, M. C. (2003). Reading growth in high-poverty classrooms: The influence of teacher practices that encourage cognitive engagement in literacy learning. Elementary School Journal, 104(1), 3-28.

Tesch, R. (1990). Qualitative research analysis types and software tools. New York, NY: Falmer.

Tharp, R. G., \& Gallimore, R. (1988). Rousing minds to life: Teaching, learning, and schooling in social context. Cambridge, UK: Cambridge University Press. 
Tivnan, T., \& Hemphill, L. (2005). Comparing four literacy reform models in highpoverty schools: Patterns of first-grade achievement. The Elementary School Journal, 105(5), 419-441. doi:10.1086/431885

Tomlinson, C. A. (2001). How to differentiate instruction in mixed-ability classrooms (2nd ed.). Alexandria, VA: Association for Supervision and Curriculum Development.

Tompkins, G. (2003). Literacy for the $21^{\text {st }}$ century: Teaching reading and writing in prekindergarten through grade 4. Upper Saddle River, NJ: Pearson Education.

Torgeson, J. K. (1998). Catch them before they fall: Identification and assessment to prevent reading failure in young children. American Education, 22, 1-8. Retrieved November 7, 2007, from http://www.aft.org/pubs-reports/americaneducator/spring-summer 98/torgeson.pdf

Van den Broek, P., \& Kremer, K. E. (2000). The mind in action: What it means to comprehend during reading. In B. M. Taylor, M. F. Graves, \& P. van den Broek (Eds.), Reading for meaning: Fostering comprehension in the middle grades (pp. 1-31). New York, NY: Teachers College Press.

Von Glaserfeld, E. (1995). A constructivist approach to teaching. In L. Steffe \& J. Gale (Eds.), Constructivism in education (pp. 3-16). Hillsdale, NJ: Lawrence Erlbaum.

Vygotsky, L. S. (1978). Mind in society: The development of higher psychology process. Cambridge, MA: Harvard University Press. (Originally published in 1930)

Vygotsky, L. (1986). Thought and language (rev. \& ed. A. Kozulin). Cambridge, MA: Massachusetts Institute of Technology Press. (Originally published in 1962).

Wertsch, J. V. (1978). Adult-child interaction and the roots of metacognition. The Quarterly Newsletter of the Institute for Comparative Human Development, 2, pp. 15-18.

Wood, D., Bruner, J., \& Ross, G. (1976). The role of tutoring in problem-solving. Journal of Child Psychology and Psychiatry, 17(2), 89-100.

Worthy, J. (1996). Removing barriers to voluntary reading for reluctant readers: The role of school and classroom libraries. Language Arts, 73, 483-492.

Yin, R. K. (2003). Case study research: Design and methods (3rd ed.). Thousand Oaks, CA: Sage.

Yin, R. K. (Ed.). (2004). The case study anthology. Thousand Oaks, CA: Sage. 
Yin, R. (2009). Case study research: Design and methods ( $4^{\text {th }}$ ed.). Thousand Oaks, CA: Sage.

Yin, R. (2014). Case study research: Design and methods ( $5^{\text {th }}$ ed.). Thousand Oaks, CA: Sage.

Yopp, H. K., \& Yopp, R. H. (2000). Supporting phonemic awareness development in the classroom. The Reading Teacher, 54(2), 130-143.

Zeichner, K. (1981). Reflective teaching in field-based experience in teacher education. Interchange, 12(4), 1-22.

Zemelman, S., Daniels, H., \& Hyde, A. (1993). Best practice: New standards for teaching and learning in America's schools. Portsmouth, NH: Heinemann. 
APPENDIX A

STUDENT ASSENT FORM 
I am willing to take part in the study called impact of Daily 5 and CAFÉ literacy framework on reading comprehension in fourth grade readers. I understand that the researcher from Portland State University is hoping to help students with reading comprehension. I understand that I will participate in interviews, surveys, draw a picture, questionnaire, achievement test and written responses to reading journals. The study will take place in my fourth grade classroom at Hogan Cedars Elementary School.

I am taking part because I want to. I have been told that I can stop at any time, and if I do not like a question, I do not have to answer it. No one will know my answers, including parents and other students.

Name

Signature

Date:

Age: 
APPENDIX B

CONSENT FORM FOR PARENTS AND GUARDIANS 


\section{PARENT \& GUARDIAN CONSENT FORM}

Your child is invited to participate in a research study conducted by Sandra Duty, who studies at Portland State University in the Curriculum and Instruction Department. I hope to discover how your child comprehends during reading instruction. Your child was selected as a possible participant in this study because reading comprehension in 4th grade is important to understand content.

If you decide to allow your child to participate, surveys, achievement tests, interviews, questionnaires, illustrations and reading journal written responses will take place in my 4th grade classroom at Hogan Cedars over a ten week time period. Interviews will be transcribed in written form and take place in the classroom bi-weekly. Surveys, tests, and questionnaires will take place in the classroom during the study.

There are no risks, discomforts, or inconveniences from this study. There are no costs to participate in this study. The benefits of the study will help students understand and comprehend reading at the 4 th grade level. The study will also help teachers to understand how students comprehend reading.

Any information that is obtained in connection with this study and that can be identified with your child will remain confidential and will be disclosed only with your permission or as required by law. Subject identities will be kept confidential by using student initials in the study. Data from the study will be locked in a file cabinet.

Your child's participation is voluntary. Your decision whether or not to allow your child to participate will not affect you or your child's relationship with my classroom or myself, as a teacher at Hogan Cedars Elementary. If you decide not to allow your child to participate, you and/or your child are free to withdraw your consent and discontinue participation at any time without penalty.

If you have any questions about the study, please feel free to contact me at Hogan Cedars Elementary School, 1770 SE Fleming Ave. The phone number is 503-674-2100 and my e-mail is duty@gresham.k12.or.us. My advisor at Portland State University is Dr. Dannelle Stevens. If you have questions regarding your rights as a research subject, please contact the IRB (irb@psu.edu). You will be offered a copy of this form to keep.

Your signature indicates that you have read and understand the information provided above, that you willingly agree to allow your child to participate, that you and/or your child may withdraw your consent at any time and discontinue participation without penalty, and that you will receive a copy of this form.

Signature Date 
APPENDIX C

INTERVIEW QUESTIONS 


\section{Interview Questions}

1. Tell me about the books you are reading, what kinds of books do you like?

2. Do you enjoy reading? What do you like about reading and the Daily 5 ? How does the Daily 5 help you understand what you are reading?

3. How does CAFÉ help you with your reading strategies?

4. How do you know when you read the words and understand what you read?

5. Do you like to select your own books to read?

6. How do you select your own books to participate in the Daily 5 ?

7. How do you reflect or think about your reading goals to improve your reading comprehension? 
APPENDIX D

READING RESPONSE JOURNAL QUESTIONS 


\section{Reading Response Journal Questions}

1. Describe what happens to you in the Daily Five?

2. What CAFÉ strategies have you learned and which ones help you become a better reader?

3. Do you like to set reading goals? Tell me about your reading goals.

4. Why do you like writing workshop? Do you participate in Daily 5 writing?

5. How do you see yourself as a reader at the beginning of the year and what is reading like now?

6. How do you describe yourself as a reader?

7. How do you feel about reading? Do you like reading? 
APPENDIX E

RESEARCH QUESTION MATRIX 
Research Question Matrix

\begin{tabular}{|c|c|c|c|c|c|c|}
\hline & \multicolumn{6}{|c|}{ Data Sources } \\
\hline & 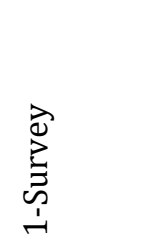 & 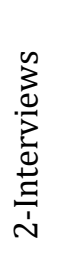 & 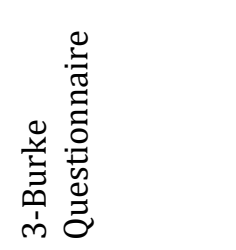 & 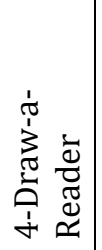 & 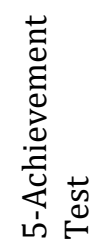 & 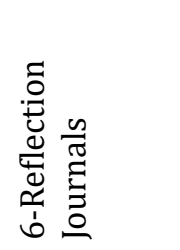 \\
\hline \multicolumn{7}{|c|}{ Question \#1: How do students perceive their experience in Daily 5 and CAFÉ reading framework? } \\
\hline $\begin{array}{l}1.1 \text { Describe what happens to you in } \\
\text { the Daily } 5 .\end{array}$ & & $\mathrm{X}$ & & $\mathrm{X}$ & & $\mathrm{X}$ \\
\hline $\begin{array}{l}\text { 1.2 What CAFÉ strategies have you } \\
\text { learned? Which ones help you } \\
\text { become a better reader and why? }\end{array}$ & & $\mathrm{X}$ & & $\mathrm{X}$ & & $\mathrm{X}$ \\
\hline \multicolumn{7}{|c|}{$\begin{array}{l}\text { Question \#2: How do students respond to the comprehension strategies taught in the Daily } 5 \text { and } \\
\text { CAFÉ reading framework? }\end{array}$} \\
\hline $\begin{array}{l}2.1 \text { How do struggling students } \\
\text { respond to specific Café reading } \\
\text { framework strategies: goal-setting, } \\
\text { writing workshop, student choice? }\end{array}$ & & $\mathrm{X}$ & & & & $\begin{array}{l}\text { 7-Goal } \\
\text { setting in } \\
\text { journals } \\
\text { 7-Reflection } \\
\text { on writing } \\
\text { during } \\
\text { writing } \\
\text { workshop }\end{array}$ \\
\hline $\begin{array}{l}2.2 \text { How do struggling students } \\
\text { respond to specific Daily } 5 \text { reading } \\
\text { framework strategies: read-to-self, } \\
\text { read-to-others, vocabulary, writing, } \\
\text { listen to reading? }\end{array}$ & & $\mathrm{X}$ & & & & $\mathrm{X}$ \\
\hline \multicolumn{7}{|c|}{ Question \#3: What are struggling students' attitudes toward reading and themselves as readers? } \\
\hline $\begin{array}{l}3.1 \text { How do you feel about reading? } \\
\text { Do you like reading? }\end{array}$ & $\begin{array}{l}\text { Garfield } \\
\text { reading } \\
\text { attitude } \\
\text { survey }\end{array}$ & $\mathrm{X}$ & & $\mathrm{X}$ & & \\
\hline $\begin{array}{l}3.2 \text { How do you see yourself as a } \\
\text { reader at the beginning of the year } \\
\text { and what is reading like now? }\end{array}$ & & $\mathrm{X}$ & & $\mathrm{X}$ & & $\mathrm{X}$ \\
\hline $\begin{array}{l}3.3 \text { How do you describe yourself as a } \\
\text { reader? }\end{array}$ & & $\mathrm{X}$ & $\begin{array}{l}\text { Burke } \\
\text { Questionnaire } \\
\# 9\end{array}$ & $\mathrm{X}$ & & $\mathrm{X}$ \\
\hline \multicolumn{5}{|c|}{$\begin{array}{l}\text { Question \#4: What kind of growth in reading comprehension did the } \\
\text { struggling students have over one year? }\end{array}$} & $\mathrm{X}$ & \\
\hline
\end{tabular}




\section{APPENDIX F}

DRAW-A-READER ILLUSTRATION 


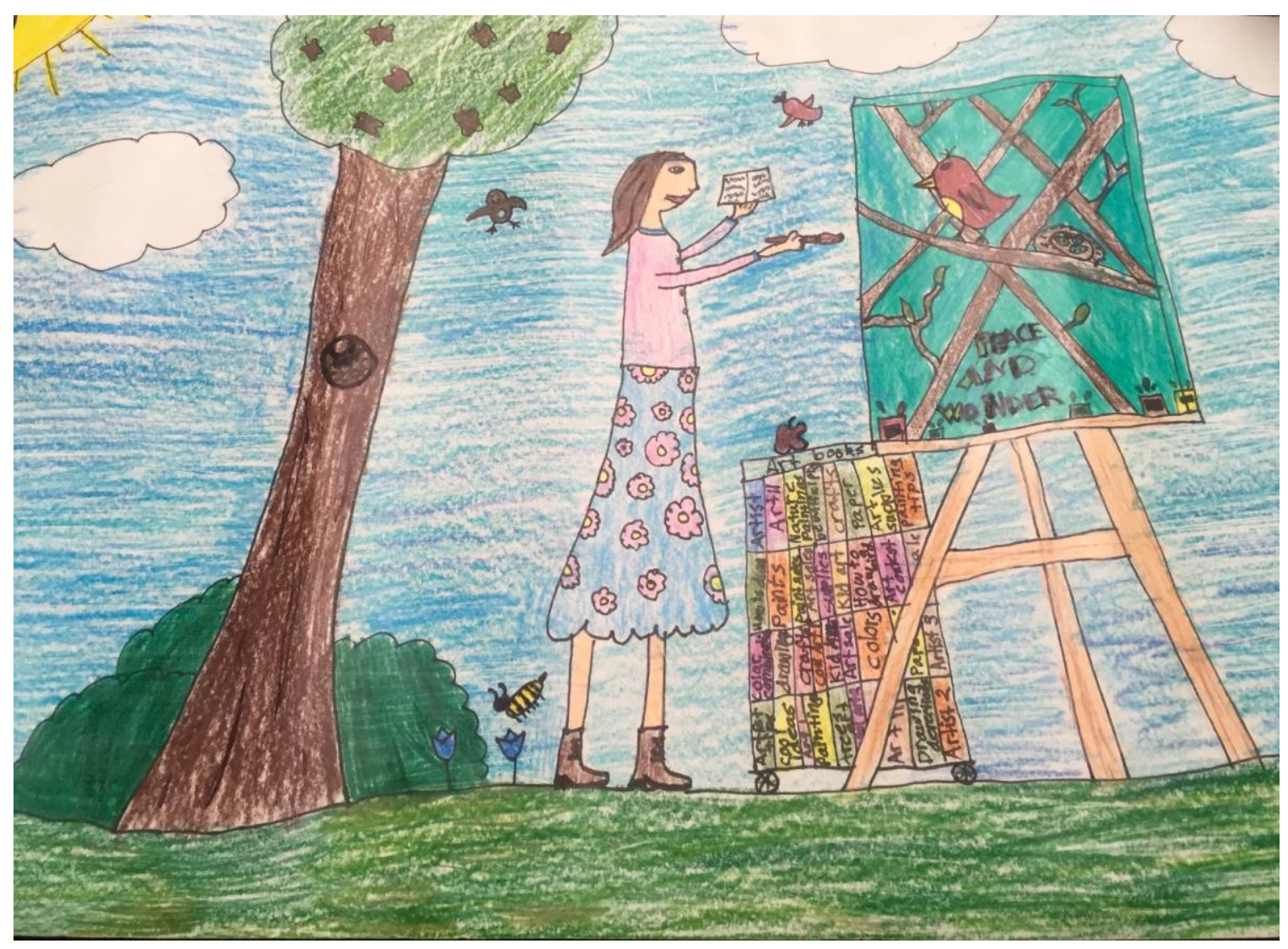

